\title{
Physical Characterization of Tropical Oceanic Convection Observed in KWAJEX
}

\author{
SAndra E. Yuter And Robert A. Houze JR. \\ Department of Atmospheric Sciences, University of Washington, Seattle, Washington \\ ERIC A. SMITH \\ NASA Goddard Space Flight Center, Greenbelt, Maryland \\ ThOMAS T. WiLheIT \\ Department of Meteorology, Texas A\&M University, College Station, Texas \\ EDWARD ZIPSER \\ Department of Meteorology, University of Utah, Salt Lake City, Utah
}

(Manuscript received 26 December 2003, in final form 23 August 2004)

\begin{abstract}
The Tropical Rainfall Measuring Mission (TRMM) Kwajalein Experiment (KWAJEX) was designed to obtain an empirical physical characterization of precipitating convective clouds over the tropical ocean. Coordinated datasets were collected by three aircraft, one ship, five upper-air sounding sites, and a variety of continuously recording remote and in situ surface-based sensors, including scanning Doppler radars, profilers, disdrometers, and rain gauges. This paper describes the physical characterization of the Kwajalein cloud population that has emerged from analyses of datasets that were obtained during KWAJEX and combined with long-term TRMM ground validation site observations encompassing three rainy seasons. The spatial and temporal dimensions of the precipitation entities exhibit a lognormal probability distribution, as has been observed over other parts of the tropical ocean. The diurnal cycle of the convection is also generally similar to that seen over other tropical oceans. The largest precipitating cloud elements-those with rain areas exceeding $14000 \mathrm{~km}^{2}$ - have the most pronounced diurnal cycle, with a maximum frequency of occurrence before dawn; the smallest rain areas are most frequent in the afternoon. The large systems exhibited stratiform rain areas juxtaposed with convective regions. Frequency distributions of dual-Doppler radar data showed narrow versus broad spectra of divergence in the stratiform and convective regions, respectively, as expected because strong up- and downdrafts are absent in the stratiform regions. The dual-Doppler profiles consistently showed low-level convergence and upper-level divergence in convective regions and midlevel convergence sandwiched between lower- and upper-level divergence in stratiform regions. However, the magnitudes of divergence are sensitive to assumptions made in classifying the radar echoes as convective or stratiform. This sensitivity implies that heating profiles derived from satellite radar data will be sensitive to the details of the scheme used to separate convective and stratiform rain areas. Comparison of airborne passive microwave data with ground-based radar data indicates that the pattern of scattering of $85-\mathrm{GHz}$ radiance by ice particles in the upper portions of KWAJEX precipitating clouds is poorly correlated with the precipitation pattern at lower levels while the emission channels $(10 \mathrm{and} 19 \mathrm{GHz})$ have brightness temperature patterns that closely correspond to the lower-level precipitation structure. In situ ice particle imagery obtained by aircraft at upper levels $(\sim 11 \mathrm{~km})$ shows that the concentrations of ice particles of all densities are greater in the upper portions of active convective rain regions and lower in the upper portions of stratiform regions, probably because the active updrafts convey the particles to upper levels, whereas in the stratiform regions sedimentation removes the larger ice particles over time. Low-level aircraft flying in the rain layer show similar total drop concentrations in and out of convective cells, but they also show a sudden jump in the concentration of larger raindrops at the boundaries of the cells, indicating a discontinuity in growth processes such as coalescence at the cell boundary.
\end{abstract}

Corresponding author address: Prof. Sandra Yuter, Department of Atmospheric Sciences, University of Washington, Box 351640, Seattle, WA 98195-1640.

E-mail: yuter@atmos.washington.edu 


\section{Introduction}

An empirical detailed physical characterization of precipitating convective cloud populations over the tropical oceans is a long-time goal of tropical meteorology. It is the basis of understanding much of the general circulation of the atmosphere. Riehl and Malkus (1958) pointed out how the deeper tropical cumulonimbus clouds are the sole conveyers of moist static energy from the ocean surface to the upper troposphere worldwide. Ooyama (1971), Yanai et al. (1973), and Arakawa and Schubert (1974) introduced simplified quantifications of convective populations as the mathematical basis for parameterization of convection in larger-scale flow patterns. These large-scale approaches invoked convective cloud models to infer the cloud population properties from large-scale sounding data.

These early studies have been followed by a quest for an empirical characterization of the tropical cloud populations. In a very early study, Dennis and Fernald (1963) described the radar echo population in the Marshall Islands from very crude radar data. The first major attempt to characterize the tropical oceanic cloud population via an organized field project was the Global Atmospheric Research Program Atlantic Tropical Experiment (GATE; Houze and Betts 1981). Out of GATE arose an appreciation of the stratiform precipitation falling from the largest members of the population (Zipser 1977; Houze 1977). As a result of GATE and other radar observations, the heating profile associated with the convective population became recognized as being made top heavy by the stratiform precipitation processes (Houze 1982, 1989). The Tropical Rainfall Measuring Mission (TRMM) satellite documents tropical precipitation and its breakdown into convective and stratiform components with passive microwave sensors and a meteorological radar (Kummerow et al. 1998). The accuracy of the precipitation retrieval by passive microwave sensors requires assumptions about the internal microphysical structure of the convective and stratiform cloud elements (Wilheit 1986; Kummerow and Giglio 1994; Smith et al. 1992). Further assumptions are made to estimate rain from the TRMM radar and to subdivide the radar data into convective and stratiform components (Awaka et al. 1998). The accuracy of the convective/stratiform separation affects the inference of the vertical distribution of heating and its impacts on the global circulation (Tao et al. 2001; Schumacher et al. 2004).

Because of the general historical need for an improved characterization of the tropical oceanic cloud population and because of the particular needs to process accurately the TRMM satellite data, a field campaign was organized as part of the TRMM ground validation (GV) (Kummerow et al. 2000) to provide an unprecedented comprehensive physical characterization of the convective cloud population surrounding

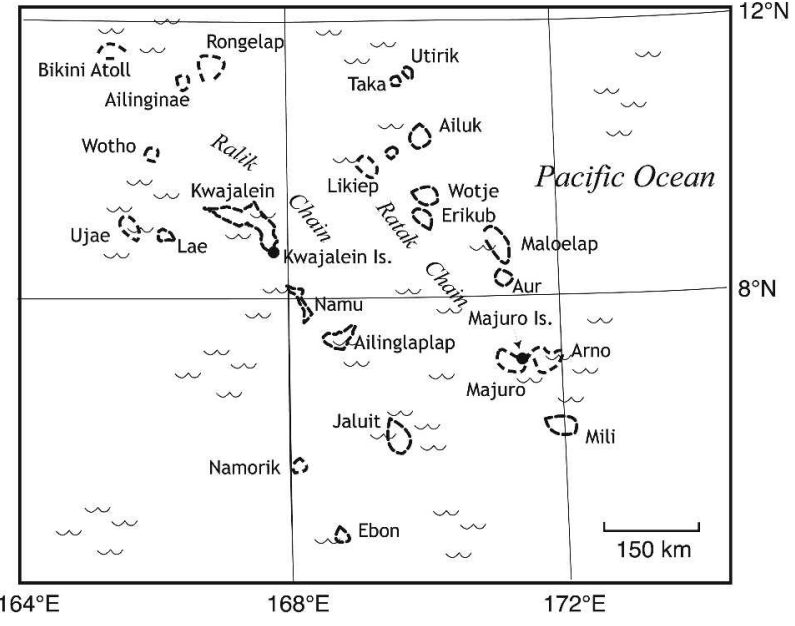

FIG. 1. Regional map of the Marshall Islands.

Kwajalein Atoll $^{1}$ in the Republic of the Marshall Islands (Figs. 1 and 2). Kwajalein Atoll has an area of $2200 \mathrm{~km}^{2}$. Kwajalein Island, the largest island in Kwajalein Atoll, is less than $15 \mathrm{~km}^{2}$ in area. The land area of the Kwajalein Atoll islands is sufficiently small to permit the region to be classified as open ocean in the TRMM Microwave Imager (TMI) algorithms (Kim et al. 2004). Kwajalein Atoll has been a TRMM GV site since the TRMM satellite launch in 1997 (Marks et al. 2000; Schumacher and Houze 2000; Adkins and Yuter 2001). Locating the field campaign at the Kwajalein GV site permitted collection of an enhanced dataset in the context of the long-term S-band radar record at the same location.

From 23 July to 15 September 1999, over 100 participants from 30 organizations participated in the Kwajalein Experiment (KWAJEX) field campaign (Tables 1 and 2). The 55 project days included 43 days at sea by the National Oceanic and Atmospheric Administration (NOAA) Ship Ronald H. Brown, 39 aircraft missions, and the successful launching of 1068 upper-air soundings of the troposphere and 101 tethered-sonde profiles of the boundary layer. During July-September, Kwajalein is located at or near the northern edge of the western Pacific Ocean ITCZ. A time-latitude plot for the KWAJEX period (Fig. 3) indicates the latitudinal variation of high cloudiness associated with the ITCZ relative to the position of Kwajalein at $8.7^{\circ} \mathrm{N}$. Monthly rainfall usually increases north to south in the vicinity of the atoll (Schumacher and Houze 2000, their Fig. 13). Westward-propagating synoptic disturbances during July-September within the equatorial western Pacific region were first systematically described by Reed and Recker (1971). They used composites of satellite data and a network of upper-air sounding stations to char-

\footnotetext{
${ }^{1}$ Local time at Kwajalein $=\mathrm{UTC}+12 \mathrm{~h}$.
} 


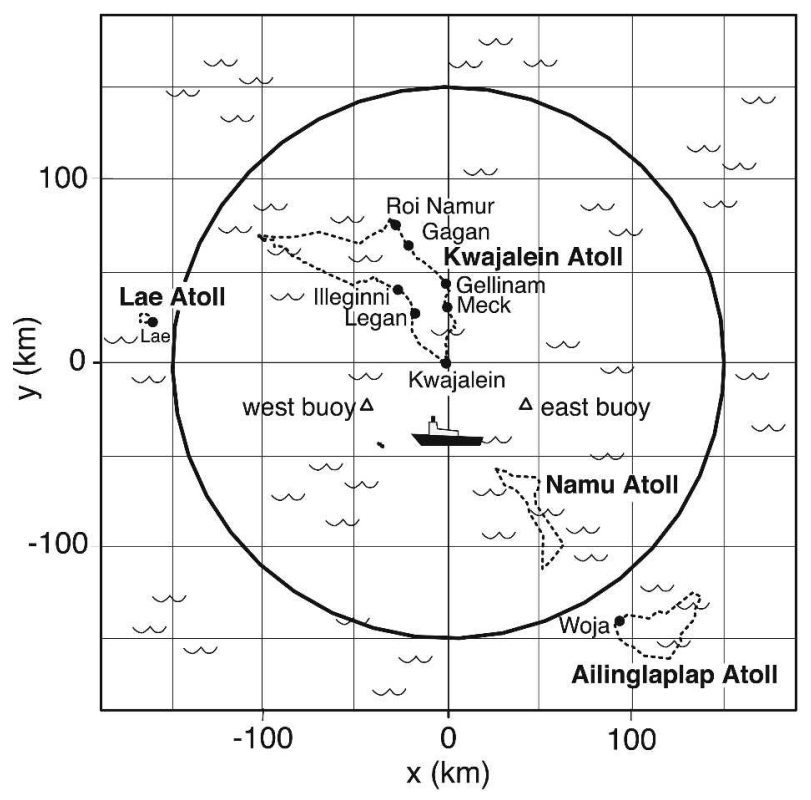

FIG. 2. Kwajalein and neighboring atoll islands with KWAJEX sensors. Locations of the NOAA Pacific Marine Environmental Laboratory (PMEL) TAO buoys and the Brown for cruise 1 are also shown. Circle indicates a $150-\mathrm{km}$ radius area.

acterize wavelength, propagation speed, and the interrelation among the cloudiness, precipitation, and wind and thermodynamic profiles in different phases of the wave. A detailed description of KWAJEX precipitation events and their relation to wave disturbances is provided in Sobel et al. (2004). The possible influences on local precipitation by tropical cyclones to the northwest of Kwajalein and by midlatitude cyclones to the north of Kwajalein are topics of active research.

In this paper we present the subset of TRMM scientific issues that the KWAJEX observations were designed to address and an analysis of the first-order characteristics of the environment and cloud population. The probability distributions of the spatial and temporal dimensions of the precipitating cloud elements are determined from radar data obtained over three years, and the diurnal behavior of the population is described. The accuracy of the subdivision of the population into convective and stratiform components is assessed with the aid of dual-Doppler radar observations obtained by a combination of ship- and atoll-based radars. The microphysical characteristics of the precipitation particles are assessed from airborne remote and in situ measurements. Acronyms and their descriptions for selected instruments can be found in Table 3 .

\section{TRMM scientific issues addressed by KWAJEX}

The KWAJEX field campaign was designed to address particular issues related to the remote measurements made by the TRMM satellite. These issues are summarized below.
TABLE 1. List of organizations and institutions participating in KWAJEX

\begin{tabular}{l}
\hline \hline \multicolumn{1}{c}{ Name } \\
\hline Aeromet, Inc. \\
California Institute of Technology/Jet Propulsion Laboratory \\
Colorado State University \\
Desert Research Institute \\
The Florida State University \\
NASA Ames Research Center \\
NASA Dryden Flight Research Center \\
NASA Goddard Space Flight Center \\
NASA Marshall Space Flight Center \\
National Center for Atmospheric Research \\
NOAA Aeronomy Laboratory \\
NOAA Atlantic Oceanographic and Meteorological \\
Laboratory \\
NOAA Environmental Technology Laboratory \\
Purdue University \\
St. Louis University \\
Stratton Park Engineering Company (SPEC), Inc. \\
Texas A\&M University \\
Texas Tech University \\
University of Alabama \\
University of Central Florida \\
University of Colorado/Cooperative Institute for Research in \\
Environmental Sciences \\
University of Houston \\
University of Iowa \\
University of Maryland/Joint Center For Earth Systems \\
Technology \\
University of North Dakota \\
University of Utah \\
University of Virginia \\
University of Washington \\
University of Washington/Applied Physics Laboratory \\
University of Wisconsin/Space Science and Engineering Center \\
Nater
\end{tabular}

\section{a. Passive microwave precipitation retrieval}

Satellite passive microwave precipitation estimation utilizes the modification of surface upwelling radiation by precipitation. A detailed discussion of the relevant physics can be found in Wilheit (1986), Mugnai and Smith (1988), and Smith and Mugnai (1988, 1989). Passive microwave brightness temperatures $T_{b}$ are sensitive to the precipitating column scattering and absorption properties, which in turn are dependent on the vertical profiles of mixing ratio by hydrometeor type of precipitation-sized particles and cloud-sized particles and by water vapor within the column. However, the vertical profile of hydrometeors is not uniquely related to surface rainfall (Wilheit 1986; Smith et al. 1992; Kummerow et al. 1998). To address some of the ambiguity in mapping sets of brightness temperatures to surface rain rate $\left(T_{b}-R_{s}\right)$, "physically based" microwave precipitation retrieval as employed in the TRMM satellite algorithms utilizes numerical cloud-model simulations of convection (Mugnai et al. 1993; Kummerow et al. 1998). Output from cloud-model simulations of the atmospheric, cloud, and precipitation characteristics of selected precipitating clouds is grouped and averaged into several surface rain-rate categories and convective and stratiform precipitation types. A for- 
TABLE 2. KWAJEX lead scientists. Multiple entries are shown for time-shared positions.

\begin{tabular}{ll}
\hline \hline \multicolumn{1}{c}{ Position } & \multicolumn{1}{c}{ Name, institution } \\
\hline Aircraft mission coordinator & $\begin{array}{l}\text { M. Biggerstaff, Texas A\&M } \\
\text { University }\end{array}$ \\
Aircraft mission coordinator & $\begin{array}{l}\text { E. Zipser, University of Utah } \\
\text { Citation chief scientist }\end{array}$ \\
& $\begin{array}{l}\text { T. Grainger, University of } \\
\text { North Dakota }\end{array}$ \\
Citation chief scientist & J. Stith, University of North \\
& Dakota \\
Convair-580 chief scientist & P. Hobbs, University of \\
& Washington \\
DC-8 chief scientist & M. Goodman, NASA MSFC \\
DC-8 chief scientist & A. Guillory, NASA MSFC \\
DC-8 chief scientist & R. Hood, NASA MSFC \\
Meck Island chief scientist & J. Fuentes, University of \\
& Virginia \\
Meck Island chief scientist & M. Garstang, University of \\
& Virginia \\
NOAA Ship Ronald H. Brown & R. Cifelli, Colorado State \\
chief scientist, cruise 1 & University \\
NOAA Ship Ronald H. Brown & C. Leary, Texas Tech \\
chief scientist, cruise 2 & University \\
Operations director & R. Houze, University of \\
& Washington \\
Operations director & E. Smith, The Florida State \\
& University \\
Operations director & T. Wilheit, Texas A\&M \\
Project science coordinator/ & University \\
operations director & S. Yuter, University of \\
\hline & Washington \\
\hline
\end{tabular}

ward radiative transfer calculation is then made for each rainfall interval/precipitation type using the averaged hydrometeor profiles to produce brightness temperatures at each of the TMI radiometer frequencies. The cloud-model and radiative transfer calculations

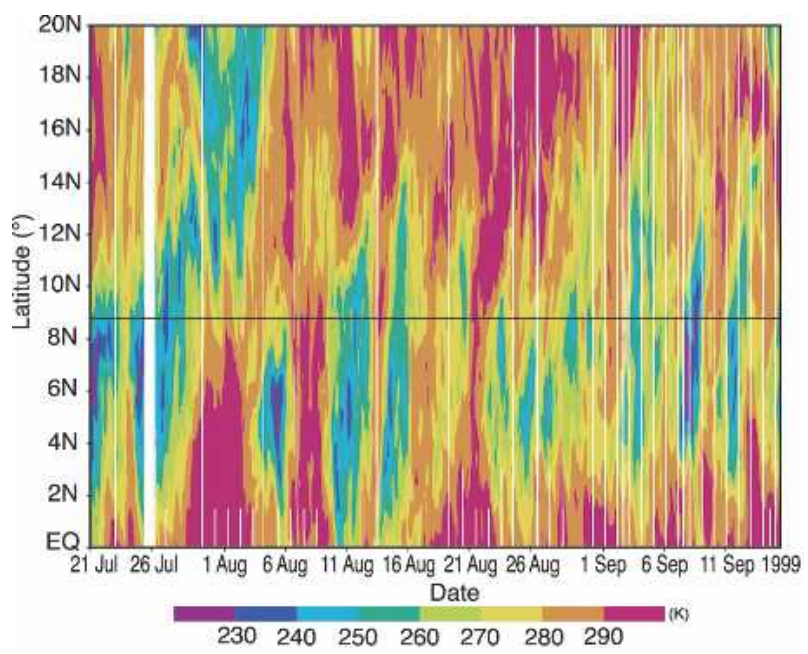

FIG. 3. Time-latitude plot of the Geostationary Meteorological Satellite IR cloud-top temperature averaged over $163^{\circ}-173^{\circ} \mathrm{E}$ longitude and $1^{\circ}$-latitude steps from $0^{\circ}$ to $20^{\circ} \mathrm{N}$. Position of Kwajalein is shown by line at $8.7^{\circ} \mathrm{N}$. (Plot provided through the courtesy of A. Sobel of Columbia University.) yield sets of brightness temperatures associated with different surface rainfall rates and precipitation types. This information is combined in a database to derive relations between $T_{b}$ and surface rainfall rates used in the TRMM microwave precipitation retrieval algorithm.

Assessment of the physical assumptions employed in the TRMM microwave algorithms involves assumptions in the radiative transfer calculations and within the numerical cloud models. For open-ocean areas, representing $\sim 73 \%$ of TRMM satellite coverage (J. Kwiatkowski 2002, personal communication), physical assumptions associated with both emission and scattering are relevant. Key issues addressable by field campaigntype datasets include the quantification of uncertainties related to treatment of horizontally inhomogeneous precipitation as uniform at the scale of the satellite field of view (e.g., beam filling), physical properties of the vertical profile of hydrometeors, and several factors that affect the realism of cloud model output.

For passive microwave applications, information on the physical properties of the vertical profile of hydrometeors is particularly needed in the low to midtroposphere at altitudes of less than the $-25^{\circ} \mathrm{C}$ level. This region of the precipitating cloud contains the highest concentration of hydrometeor mass and the largest particles (Hobbs 1974). At altitudes above the $-25^{\circ} \mathrm{C}$ level, the ice scattering represents only a small portion of the integrated column scattering sensed by the passive microwave instruments. Radiative transfer cal-

TABLE 3. Acronyms for selected instruments.

\begin{tabular}{|c|c|}
\hline Abbreviation & Description \\
\hline $2 \mathrm{DC}$ & $\begin{array}{l}\text { Two-dimensional cloud probe (on DC- } 8 \text { Droplet } \\
\text { Measurement Technology, Inc.; on other } \\
\text { aircraft Particle Measuring Systems, Inc.) }\end{array}$ \\
\hline 2DP & $\begin{array}{l}\text { Two-dimensional precipitation probe (on DC-8 } \\
\text { Droplet Measurement Technology, Inc.; } \\
\text { on other aircraft Particle Measuring } \\
\text { Systems, Inc.) }\end{array}$ \\
\hline AMMR & $\begin{array}{l}\text { Airborne Multichannel Microwave Radiometer } \\
\text { (NASA GSFC) }\end{array}$ \\
\hline AMPR & $\begin{array}{l}\text { Advanced Microwave Precipitation Radiometer } \\
\text { (NASA MSFC) }\end{array}$ \\
\hline ARMAR & Airborne Rain-Mapping Radar (JPL) \\
\hline CPI & Cloud Particle Imager (SPEC, Inc.) \\
\hline DADS & $\begin{array}{l}\text { Data Acquisition and Distribution System } \\
\text { (NASA DC-8) }\end{array}$ \\
\hline HVPS & $\begin{array}{l}\text { High-Volume Precipitation Sampler } \\
\text { (SPEC, Inc.) }\end{array}$ \\
\hline IMET & $\begin{array}{l}\text { Improved meteorology system (Woods Hole } \\
\text { Oceanographic Institute) }\end{array}$ \\
\hline PR & Precipitation radar (sensor on TRMM satellite) \\
\hline SCS & $\begin{array}{l}\text { Scientific Computer System (NOAA Ship } \\
\text { Ronald H. Brown) }\end{array}$ \\
\hline S-HIS & $\begin{array}{l}\text { Scanning High-Resolution Interferometer } \\
\text { Sounder (University of Wisconsin) }\end{array}$ \\
\hline TMI & $\begin{array}{l}\text { TRMM Microwave Imager (sensor on TRMM } \\
\text { satellite) }\end{array}$ \\
\hline TRMM & $\begin{array}{l}\text { Tropical Rainfall Measuring Mission (NASA } \\
\text { satellite) }\end{array}$ \\
\hline
\end{tabular}


culations are particularly sensitive to assumptions about the relative amounts of liquid and ice hydrometeors at altitudes within and just above the melting layer, corresponding to temperatures from $\sim 0^{\circ}$ to $-10^{\circ} \mathrm{C}$, and to the cloud liquid water content (Smith and Mugnai 1989; Tesmer and Wilheit 1998). Direct observations of these quantities within precipitating clouds over the tropical open ocean are scarce, and so it has been difficult to evaluate cloud model simulations for this region.

The quality of cloud-model output depends on the data used to initialize the simulation and the veracity of the models' physics and physical assumptions. Observations needed for cloud-model input include thermodynamic and wind profiles from the surface to the lower stratosphere, boundary layer measurements, and surface fluxes. Cloud-resolving models have been shown to be sensitive to the detailed structure in the boundary layer and to the spatial and temporal variability of vertical wind shear and water vapor (Lucas et al. 2000). Upper-air soundings are needed simultaneously at several different locations within the domain and at high time resolution to characterize the horizontal and temporal variation of environmental characteristics. The microphysics and dynamics of the cloud model can be assessed by evaluation of cloud-model output in comparison with in situ microphysics data and remotely sensed characteristics of the precipitation and wind structure.

\section{b. Spaceborne radar precipitation retrieval}

The spaceborne $\mathrm{K}_{\mathrm{u}}$-band $(2.17 \mathrm{~cm})$ precipitation radar (PR) aboard the TRMM satellite senses precipitation over the ocean in terms of transmitted energy that is backscattered from precipitation and the ocean surface. As compared with the $\mathrm{C}$ or $\mathrm{S}$ band, which is typically used for ground-based weather radars, the $\mathrm{K}_{\mathrm{u}^{-}}$ band energy is strongly attenuated by rainfall (Battan 1973; Meneghini and Kozu 1990). A potentially large source of error in TRMM PR products is associated with the attenuation correction that is applied to the PR measurements before being further processed into reflectivity profiles, convective/stratiform maps, and rainrate maps. In the TRMM PR algorithm, total pathintegrated attenuation from the spacecraft to the surface is estimated using the layer-by-layer top-down accumulating Hitschfeld and Bordan (1954) scheme in combination with a surface reference technique (Meneghini et al. 2000). The derived profile of attenuation is distributed over the vertical reflectivity profile utilizing assumptions regarding the raindrop size distribution (RDSD; Iguchi et al. 2000).

Key physical assumptions in the estimation of total path-integrated attenuation with the surface reference method are that rain has little to no effect on ocean surface backscatter at capillary scale (a few centimeters) and that the wind speeds in the reference area and rain area are similar. In addition, to refine the distribution of attenuation over the vertical profile, information on the long-term mean statistical characteristics of the RDSD with height at spatial scales that are similar to the PR effective beamwidth is needed. Nonattenuated reflectivity profiles at similar spatial scales to the TRMM PR are also needed to compare with the attenuation-corrected profiles.

The classification of radar echo into convective and stratiform precipitation types (Houze 1997) is one of the important derived products of the TRMM PR. Convective and stratiform precipitation types have distinct vertical profiles of latent heating (Houze 1989, 1997), which in turn influence circulations within the largerscale atmosphere outside of the mesoscale convective systems (Mapes and Houze 1995). Within the TRMM context, a primary application of the convective/ stratiform maps is to partition the vertically integrated heating (rainfall minus evaporation) (e.g., Schumacher et al. 2004). The TRMM PR convective/stratiform classification algorithm is based on the vertical and horizontal characteristics of radar reflectivity (Awaka et al. 1998). In the Tropics, the horizontal divergence of the wind is proportional to the vertical gradient of the heating profile (Mapes and Houze 1995). Independent measurements of the vertical profile of horizontal divergence (e.g., by Doppler radar) offer a way to evaluate how well the TRMM convective/stratiform classification separates the components of latent heating.

\section{KWAJEX field campaign observations}

The KWAJEX observation strategy was designed to optimize the gathering of data directly related to the scientific issues summarized in section 2 within the logistical constraints imposed by the geography and politics of the Kwajalein region and the available resources. Much of Kwajalein Atoll is leased to the U.S. Army as part of the U.S. Army Kwajalein Atoll (USAKA) Kwajalein Missile Range. Collaboration with USAKA was essential in basing instruments on leased islands within Kwajalein Atoll and on the outlying islands of Lae and Woja (Fig. 2). The frequency of TRMM satellite overpasses over the KWAJEX study area was lower when compared with TRMM field campaigns at higher latitudes (Kummerow et al. 2000). Based on analysis of the Kwajalein GV site data, less than 15 TRMM PR swath overpasses per month with precipitation in the study domain were expected in July-September. The swath width of the PR $(220 \mathrm{~km})$ is less than one-third of the TMI swath width $(760 \mathrm{~km})$, and so TMI overpasses were more frequent. An early decision in the project planning was to take advantage of the satellite overpasses when they occurred and to target data collection of precipitation in nonoverpass periods. 
TABLE 4. Summary of key sensors on KWAJEX aircraft. Further details on the cloud microphysics instrumentation are presented in Kingsmill et al. (2004).

\begin{tabular}{|c|c|c|c|c|c|}
\hline Type & Measurement & Instrument & DC-8 & Citation & Convair-580 \\
\hline In situ meteorological & Temperature, dewpoint, specific humidity, wind & Various & $\mathrm{X}$ & $\mathrm{X}$ & $\mathrm{X}$ \\
\hline \multirow[t]{6}{*}{ In situ cloud physics } & Cloud liquid water content & Hotwire & & $\mathrm{X}$ & $\mathrm{X}$ \\
\hline & Cloud droplet small ice spectra & $\begin{array}{l}\text { Forward } \\
\text { scattering }\end{array}$ & $\mathrm{X}$ & $\mathrm{X}$ & $\mathrm{X}$ \\
\hline & Optical array: cloud particle size and shape & 2DC & $\mathrm{X}$ & $\mathrm{X}$ & $\mathrm{X}$ \\
\hline & Optical array: precipitation particle size and shape & 2DP & $\mathrm{X}$ & & $\mathrm{X}$ \\
\hline & $\begin{array}{l}\text { Optical array: cloud and precipitation particle size } \\
\text { and shape }\end{array}$ & HVPS & & $\mathrm{X}$ & $\mathrm{X}$ \\
\hline & $\begin{array}{l}\text { Digital photograph: cloud and precipitation particle } \\
\text { size and shape }\end{array}$ & CPI & $\mathrm{X}$ & $\mathrm{X}$ & $\mathrm{X}$ \\
\hline \multirow[t]{3}{*}{ Downward looking } & Microwave radiometer $(10.7,19.35,37.1,85.5 \mathrm{GHz})$ & AMPR & $\mathrm{X}$ & & \\
\hline & $\mathrm{K}_{\mathrm{u}}$-band radar $Z, V_{r}$ (Doppler radial velocity) & ARMAR & $\mathrm{X}$ & & \\
\hline & Temperature and water vapor & S-HIS & $\mathrm{X}$ & & \\
\hline Upward looking & Microwave radiometer ( 21 and $37 \mathrm{GHz}$ ) & AMMR & & & $\mathrm{X}$ \\
\hline
\end{tabular}

\section{a. Aircraft measurements}

Given the low frequency and nearly instantaneous duration of the TRMM satellite overpasses, sensors that could stand in for the TMI and PR were needed to obtain a reasonable sample size of satellite-like data. During KWAJEX, the National Aeronautics and Space Agency (NASA) Dryden Flight Research Center DC-8 aircraft (Table 4) was equipped with the Marshall Space Flight Center (MSFC) Advanced Microwave Precipitation Radiometer (AMPR; Spencer et al. 1994), a scanning downward-looking passive microwave instrument similar to the TRMM satellite's TMI, and with the Jet Propulsion Laboratory (JPL) Airborne Rain-Mapping Radar (ARMAR), a scanning downward-looking $\mathrm{K}_{\mathrm{u}}$-band radar with characteristics similar to those of the satellite's PR (Durden et al. 1994, 2003). The nominal flight altitude of the DC-8 of $\sim 12 \mathrm{~km}$ yielded passive microwave and $\mathrm{K}_{\mathrm{u}}$-band radar data at higher horizontal spatial resolution relative to the TRMM satellite instrument's field of view. These data could either be used at their native horizontal resolutions (0.34-1.7 km for AMPR, depending on frequency, and $800 \mathrm{~m}$ for ARMAR) or could be degraded in resolution for a variety of studies examining beam filling and the interrelation of $T_{b}$ at different frequencies within tropical open-ocean convection. The DC-8 was also equipped with several types of microphysics probes to obtain statistics on the size distribution of cloud and precipitation particles at flight level (Table 4).

While the ARMAR and AMPR obtained downwardlooking remotely sensed characteristics of the vertical profile of hydrometeors, two aircraft flying in patterns beneath the DC-8 flight track collected flightlevel meteorological data, in situ microphysics data, and remotely sensed upward-looking data. The University of North Dakota (UND) Cessna Citation aircraft was the primary microphysics aircraft during KWAJEX. It was equipped with several types of microphysics probes (Table 4) to obtain statistics on the size distribution of cloud and precipitation particles and to obtain images of a subset of those particles for detailed examination of particle type and degree of riming (Stith et al. 2002). The University of Washington (UW) Convair-580 (Hobbs 2000) was equipped with a combination of microphysics probes similar to those on the Citation and an upward-looking radiometer (Table 4). The Convair also obtained aerosol measurements around convective clouds (Kaneyasu et al. 2001).

The most commonly flown flight pattern was a vertical stack of aircraft flying along the same horizontal track within different altitude blocks (Fig. 4). These flight patterns provided closely coordinated microphysics and remotely sensed data on the vertical profile of hydrometeors. Aircraft sampling was directed by an aircraft mission coordinator (Table 2) in the KWAJEX Operations Center with access to flight tracks overlaid on near-real-time scanning radar data. The aircraft coordinator suggested the timing and locations for flight tracks based on the evolving patterns of radar data and communicated this information to the aircraft. When aircraft were operating independently, flight patterns such as descending spirals within stratiform precipitation were also flown (Heymsfield et al. 2002).

Thirty-nine aircraft missions were flown during KWAJEX. The NASA DC-8 and UND Citation flew only during daylight, and so roughly one-half of the possible TRMM overpasses were sampled. Detailed information on each mission is presented in Table 5. Summary information on the aircraft component of KWAJEX is presented in Table 6. Thirty-five hours of in-cloud data were collected each by the DC- 8 and Citation. All three aircraft suffered sporadic breakdowns of equipment, primarily as a result of the harsh operating environment. Figure 5 shows the distribution of flight hours flown within cloud by temperature. The distribution of flight time was weighted toward temperatures from $2^{\circ}$ to $-10^{\circ} \mathrm{C}$, in accordance with the scientific priorities in section 2 . 

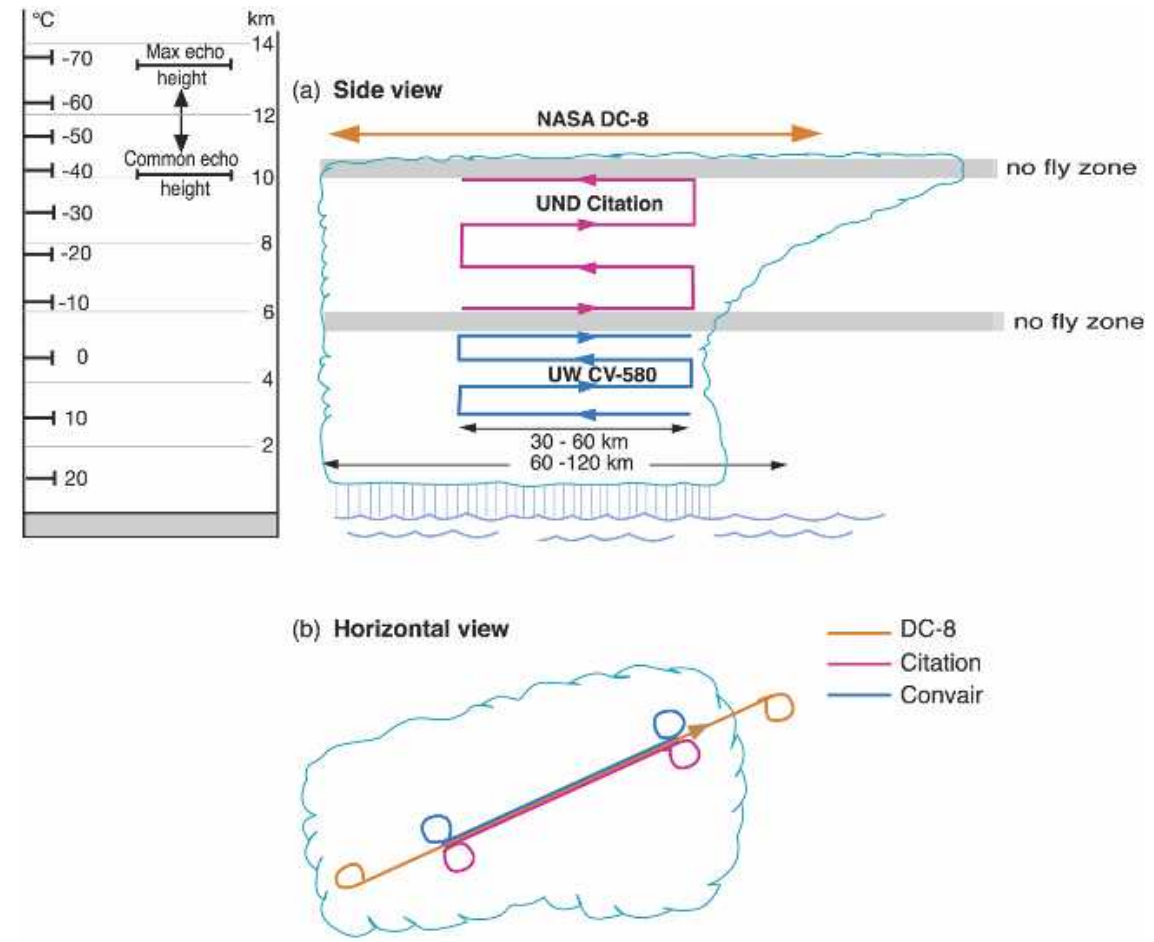

FIG. 4. Schematic of multiple aircraft mission flight tracks. (a) Side (vertical) view of flighttrack pattern showing DC-8, Citation, and Convair-580 flight-track legs. The altitude steps shown are for illustration; in practice these steps were adapted to the particular cloud and set of aircraft involved in the mission. In a similar way, flight-track leg length varied depending on the horizontal dimension of the precipitating region. Shading indicates "no fly" zones to maintain aircraft altitude separation. (b) Horizontal view of a typical flight-track pattern with all three aircraft flying straight line tracks with $90^{\circ}-270^{\circ}$ turns at the end of each leg.

Subsequent to the field campaign, the subset of flight legs flown by each aircraft suitable for microphysics data processing was identified and prioritized from 1 (lowest) to 5 (highest) by overlying flight tracks on Kwajalein S-band radar reflectivity data. The microphysical legs were identified for periods during which the aircraft were within $\sim 150-\mathrm{km}$ range of Kwajalein (i.e., within S-band radar coverage), at least one of the microphysical probes on an aircraft was functional, and the aircraft was nearby or within radar echo. Higher priority ratings were given to flight legs that sampled more intense echo and had longer durations of flight time within echo. Additional priority points were given for spirals, legs within $20 \mathrm{~min}$ of a TRMM overpass, and multiple aircraft legs. The number and average priority rating of the microphysical legs for each mission are shown in Table 5.

The community of microphysics data users from the TRMM field campaigns includes not only cloud physics specialists but also satellite algorithm developers and a variety of other scientists (e.g., Fiorino and Smith 2004, manuscript submitted to J. Appl. Meteor.). The microphysical data processing requirements to address the needs of these myriad users motivated the defini- tion of common formats for flight-level meteorological data and aircraft microphysics data and the development of software to process the TRMM field campaign aircraft microphysics datasets (Kingsmill et al. 2004).

\section{b. Surface-based radar measurements}

Two scanning Doppler radars-an S-band radar on Kwajalein Island and a C-band radar on the Brown (appendix A)-were coordinated to obtain threedimensional precipitation structure within $150 \mathrm{~km}$ of Kwajalein and dual-Doppler wind data within dualDoppler lobes during the field campaign. Two configurations of dual-Doppler lobes were used during the project, with the ship positioned $40 \mathrm{~km}$ south and $40 \mathrm{~km}$ southwest of Kwajalein Island (Fig. 6).

The S-band radar was used to direct aircraft to radar echoes, to obtain measurements of the three-dimensional precipitation structure, and to collect Doppler winds. The USAKA operational requirements constrained the S-band radar to scan $360^{\circ}$ rather than in the $<90^{\circ}$ sector scans usually employed in research radar scan strategies. Considerations associated with the dual-Doppler analysis and the desire for frequent updates of the radar data for direction of aircraft from the 
TABLE 5. Detailed summary of each aircraft mission. TRMM TMI and PR columns indicate whether a satellite overpass occurred within the mission area. Microphysics legs refer to analysis legs defined online (www.atmos.washington.edu/kwajex/ops-web/ prioritylegs).

\begin{tabular}{|c|c|c|c|c|c|c|c|}
\hline \multirow{3}{*}{$\begin{array}{l}\text { Time (UTC), } \\
\text { day, and month }\end{array}$} & \multirow[b]{3}{*}{ Aircraft involved } & \multirow{2}{*}{\multicolumn{2}{|c|}{ TRMM }} & \multirow[b]{3}{*}{ Comment } & \multicolumn{3}{|c|}{ Microphysics legs } \\
\hline & & & & & & & Avg \\
\hline & & TMI & PR & & No. & Min & priority \\
\hline $213125 \mathrm{Jul}$ & Convair & & & Test flight (with sounding spiral) & 0 & - & - \\
\hline $223526 \mathrm{Jul}$ & Citation & & & Test flight & 0 & - & - \\
\hline $054728 \mathrm{Jul}$ & Convair & $\mathrm{X}$ & $\mathrm{X}$ & Microphysics & 1 & 10 & 5 \\
\hline $024330 \mathrm{Jul}$ & Convair, DC-8 & & & $\begin{array}{l}\text { DC- } 8 \text { test flight/test of multiple } \\
\text { aircraft coordination }\end{array}$ & 15 & 122 & 2.7 \\
\hline 06201 Aug & Convair, Citation & $\mathrm{X}$ & $\mathrm{X}$ & Microphysics & 15 & 113 & 3.3 \\
\hline 02482 Aug & Convair & & & Non-KWAJEX aerosol flight & 0 & - & - \\
\hline 03353 Aug & Convair, DC-8 & & & Microphysics/remote sensing & 19 & 178 & 3.3 \\
\hline 02596 Aug & Convair, DC-8 & $\mathrm{X}$ & $\mathrm{X}$ & Microphysics & 18 & 83 & 3.6 \\
\hline 03158 Aug & Convair & & & Tethersonde intercomparison & 0 & - & - \\
\hline 22199 Aug & Convair, DC-8 & & & Microphysics/remote sensing & 17 & 112 & 2.8 \\
\hline 032110 Aug & Citation & & & Microphysics & 17 & 91 & 2.5 \\
\hline 213011 Aug & Citation, Convair, DC-8 & & & Remote sensing/microphysics & 19 & 224 & 4.9 \\
\hline 031513 Aug & Citation & & & Wind system calibration & 0 & - & - \\
\hline 231414 Aug & Citation, DC-8 & $\mathrm{X}$ & $\mathrm{X}$ & Remote sensing/microphysics & 15 & 55 & 3.3 \\
\hline 221016 Aug & Citation, DC-8 & $\mathrm{X}$ & $\mathrm{X}$ & $\begin{array}{l}\text { Radiosonde intercomparisons } \\
\text { with Meck and ship }\end{array}$ & 0 & - & - \\
\hline 192917 Aug & Citation, DC-8 & $\mathrm{X}$ & & Remote Sensing/Microphysics & 49 & 211 & 3.0 \\
\hline $021318 \mathrm{Aug}$ & Citation & & & Microphysics & 0 & - & - \\
\hline 192619 Aug & Citation, DC-8 & $\mathrm{X}$ & $\mathrm{X}$ & Remote sensing/microphysics & 24 & 205 & 3.9 \\
\hline 185722 Aug & Citation, DC-8 & & & Remote sensing/microphysics & 12 & 124 & 3.2 \\
\hline 011023 Aug & Citation, Convair, DC- 8 & & & Remote sensing/microphysics & 31 & 269 & 3.2 \\
\hline 020224 Aug & Citation, Convair, DC-8 & $\mathrm{X}$ & $\mathrm{X}$ & Remote sensing/microphysics & 11 & 67 & 1.4 \\
\hline $035625 \mathrm{Aug}$ & Citation, Convair, DC-8 & & & Remote sensing/microphysics & 23 & 190 & 2.5 \\
\hline 032626 Aug & Citation, Convair, DC-8 & $\mathrm{X}$ & $\mathrm{X}$ & $\begin{array}{l}\text { HIS calibration/ remote sensing/ } \\
\text { microphysics }\end{array}$ & 39 & 153 & 2.4 \\
\hline 215027 Aug & Convair & & & Microphysics & 5 & 40 & 5.0 \\
\hline 025528 Aug & Citation, Convair, DC-8 & & & Remote sensing/microphysics & 28 & 146 & 2.4 \\
\hline 230428 Aug & Citation, DC-8 & & & Remote sensing/microphysics & 40 & 304 & 3.9 \\
\hline 012430 Aug & Convair & $\mathrm{X}$ & & Microphysics & 20 & 196 & 3.2 \\
\hline $185730 \mathrm{Aug}$ & Citation, Convair, DC-8 & $\mathrm{X}$ & & Remote sensing/microphysics & 49 & 357 & 2.5 \\
\hline 23311 Sep & Citation, DC-8 & $\mathrm{X}$ & $\mathrm{X}$ & Remote sensing/microphysics & 26 & 116 & 2.4 \\
\hline 19012 Sep & Citation, DC-8 & & & Remote sensing/microphysics & 11 & 96 & 3.5 \\
\hline 01083 Sep & Citation, DC-8 & & & Remote sensing/microphysics & 12 & 190 & 3.9 \\
\hline 19014 Sep & DC-8 & & & Remote sensing/microphysics & 28 & 245 & 2.9 \\
\hline $21565 \mathrm{Sep}$ & Citation, DC-8 & $\mathrm{X}$ & & Remote sensing/microphysics & 46 & 219 & 2.5 \\
\hline $00198 \mathrm{Sep}$ & Citation, DC-8 & & & Remote sensing/microphysics & 42 & 340 & 3.0 \\
\hline 19568 Sep & Citation, DC-8 & $\mathrm{X}$ & $\mathrm{X}$ & Remote sensing/microphysics & 25 & 128 & 2.6 \\
\hline 192610 Sep & Citation, DC-8 & $\mathrm{X}$ & $\mathrm{X}$ & Remote sensing/microphysics & 35 & 288 & 2.9 \\
\hline $185511 \mathrm{Sep}$ & Citation, DC-8 & & & Remote sensing/microphysics & 38 & 241 & 2.4 \\
\hline 221712 Sep & DC-8 & & & HIS water vapor retrievals & 0 & - & - \\
\hline 030914 Sep & Citation, DC-8 & & & Remote sensing/microphysics & 43 & 262 & 3.0 \\
\hline Total & & & & & 773 & 5375 & \\
\hline
\end{tabular}

KWAJEX Operations Center and for rainfall mapping ${ }^{2}$ constrained the duration of coordinated volume scans to $\sim 5$ min (appendix A).

Several other surface-based radars were deployed during KWAJEX to address objectives related to the vertical distribution of hydrometeors, ocean surface scattering, and the three-dimensional structure of precipitation and winds. Vertically pointing S-band and 915-GHz profilers were deployed on the Brown (Table

\footnotetext{
${ }^{2}$ Rainfall maps based on the lowest-elevation-angle $\left(0.4^{\circ}\right)$ data can be obtained from each of the volume scans (10 times per hour).
}

7) and Legan Island (Table 8) to obtain information on characteristics of the vertical profile of raindrop spectra in particular (Gage et al. 2002) and on precipitationsized hydrometeors in general. The $915-\mathrm{GHz}$ profilers also provided high-temporal-resolution profiles of hori-

TABLE 6. Summary of aircraft missions flown during KWAJEX.

\begin{tabular}{llcc}
\hline \hline & $\begin{array}{c}\text { NASA } \\
\text { DC-8 }\end{array}$ & $\begin{array}{c}\text { UND } \\
\text { Citation }\end{array}$ & $\begin{array}{c}\text { UW } \\
\text { Convair }\end{array}$ \\
\hline Aircraft missions & 28 & 26 & 17 \\
With TRMM overpass & 15 & 13 & 8 \\
Flight hours & 97.6 & 78.9 & 58.7 \\
Hours in cloud & 35 & 34.5 & 15.4 \\
\hline
\end{tabular}




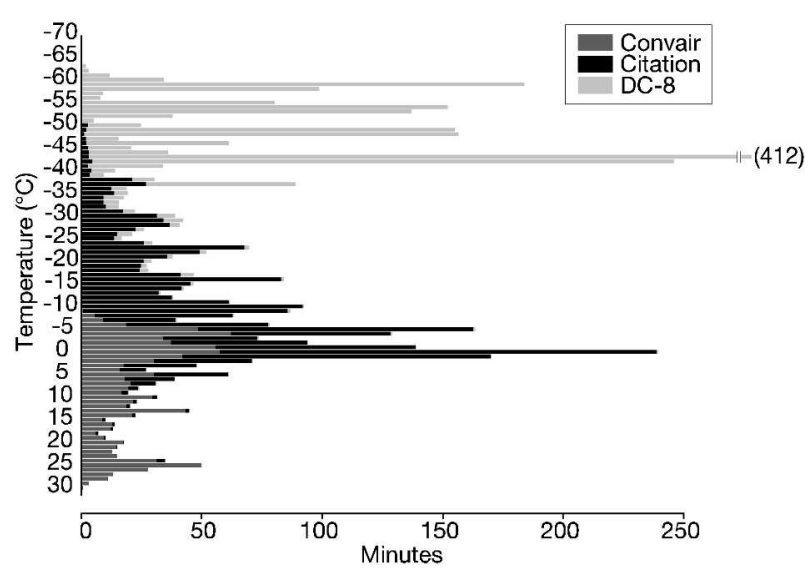

FIG. 5. Histogram of minutes within cloud at $1^{\circ} \mathrm{C}$ air temperature intervals for the three KWAJEX aircraft.

zontal winds. To address objectives related to quantifying ocean scattering at centimeter scales under different rain-rate and wind conditions, a downward-looking $\mathrm{K}_{\mathrm{u}}$-band radar was mounted on the Brown to obtain measurements of the normalized radar cross section of the ocean at incidence angles overlapping those used by the TRMM PR and the Quick Scatterometer (QuikSCAT; Contreras et al. 2003).

\section{c. Surface-based environment measurements}

The thermodynamic, wind, and radiative characteristics of the environment were observed using a closed array of upper-air sounding stations on the Brown and on Kwajalein, Roi-Namur, Lae, Woja, and Meck Islands (Table 9); a suite of instrumentation on the Brown (Table 7); and surface meteorological and oceanographic measurements from two NOAA Tropical Atmosphere-Ocean (TAO) buoys (Fig. 2). In addition, shortwave, longwave, and microwave radiometers were deployed on the Brown and on Meck Island (Tables 7 and 10). Meck Island, located on the windward side of Kwajalein Atoll, was also the site of intensive boundary layer and surface flux measurements for which a suite of instruments was deployed similar to those used in the TRMM Brazilian Large-Scale Biosphere-Atmosphere (LBA) field campaign (Betts et al. 2002). A meteorological tower and vertically pointing Doppler sound detection and ranging system (sodar) collected continuous measurements to provide context for 101 successful tethered-balloon deployments to a maximum altitude of $1500 \mathrm{~m}$ (Table 10). Isotope measurements of water vapor were made on the Brown to distinguish between evaporation from the sea surface and evaporation from precipitation (Lawrence and Gedzelman 2003). To provide a visual context for these observations, panoramas of digital cloud photos were obtained at Kwajalein three times per day at 2000, 0100, and 0600 UTC $(0800,1300$, and 1800 LT).

Upper-air soundings were obtained at 3-hourly inter-
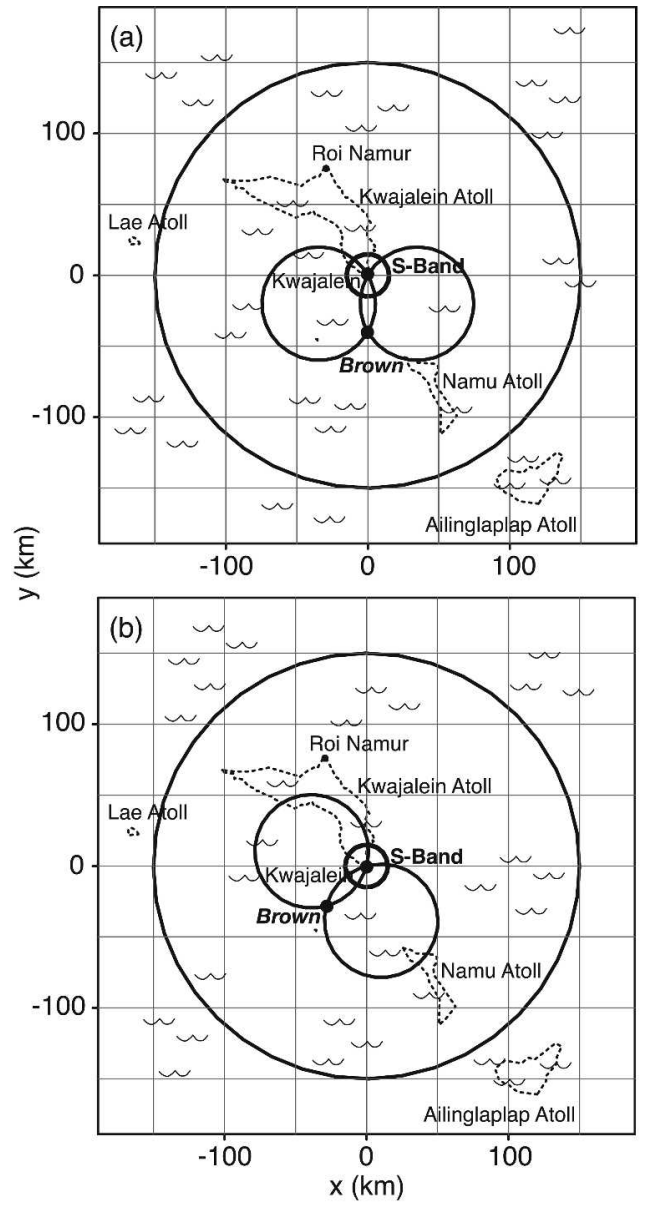

FIG. 6. Map showing dual-Doppler lobes when the Brown was (a) $40 \mathrm{~km}$ south of the Kwajalein S-band radar during cruise 1 from $28 \mathrm{Jul}$ to 19 Aug and (b) $40 \mathrm{~km}$ southwest of the radar during cruise 2 from 24 Aug to 12 Sep.

vals from the Brown while on station and at 3- to 12-h intervals at the other locations, depending on meteorological conditions and aircraft mission status. A constraint on rawinsonde operations near Kwajalein Atoll is the presence of the U.S. Army's 6-MW Advanced Research Project Agency Long-Range Tracking and Identification Radar (ALTAIR) on Roi-Namur Island, which operates at a frequency close to that of the Vaisala, Inc., and VIZ, Inc., GPS sonde frequencies. The older non-GPS Meteorological Sounding System (MSS) operating at a different frequency had to be used on Roi-Namur, Kwajalein, and Meck Islands. Interference from the ALTAIR may have contributed to intermittent problems in tracking the sonde and obtaining winds from the Vaisala GPS sondes launched from the Brown.

A detailed analysis of the upper-air sounding data collected during KWAJEX is presented in Sobel et al. (2004). The quality-controlled project-averaged sounding is shown in Fig. 7. The average temperature profiles among the KWAJEX sounding sites were very similar. 
TABLE 7. Instrumentation on NOAA Ship Ronald H. Brown during KWAJEX.

\begin{tabular}{|c|c|}
\hline Measurement & Instrument/system \\
\hline 3D structure of precipitation and radial velocity & Scanning C-band Doppler radar \\
\hline Tropospheric wind, temperature, and $\mathrm{RH}$ & Vaisala GPS upper-air sounding \\
\hline $\begin{array}{l}\text { Navigation, thermosalinograph, surface meteorological, rain } \\
\text { gauges }\end{array}$ & NOAA SCS, Woods Hole Oceanographic Institution IMET \\
\hline Precipitation profiles & NOAA Aeronomy Laboratory S-band profiler \\
\hline $\begin{array}{l}\text { Scattering off ocean surface at TRMM PR angle and frequency } \\
\text { with and without rainfall }\end{array}$ & UW Applied Physics Laboratory $\mathrm{K}_{\mathrm{u}}$-band radar \\
\hline $\begin{array}{l}\mathrm{H} \text { and } \mathrm{O} \text { isotopes to distinguish evaporation from rain vs } \\
\text { seawater }\end{array}$ & $\begin{array}{l}\text { University of Houston sample collection of water vapor and } \\
\text { rain }\end{array}$ \\
\hline Polarized emission from rain and ocean surface & $\begin{array}{l}\text { NOAA Environmental Technology Laboratory (ETL) scanning } \\
\text { microwave polarimeters }(10,15 \text {, and } 37 \mathrm{GHz})\end{array}$ \\
\hline Motion-corrected turbulent fluxes & NOAA ETL air-sea flux system \\
\hline Cloud-base height & NOAA ETL ceilometer \\
\hline Lower-tropospheric winds & NOAA ETL 915-MHz wind profiler \\
\hline Sea-air temperature difference and SST & NOAA ETL 5-mm scanning radiometer \\
\hline Column water vapor and liquid & NOAA ETL water vapor/liquid radiometers $(23.87,31.65 \mathrm{GHz})$ \\
\hline Drop size distribution & Piezoelectric disdrometer \\
\hline
\end{tabular}

Time mean differences in temperatures at the same altitude among the sites were less than $0.3^{\circ} \mathrm{C}$. The mean $0^{\circ} \mathrm{C}$ level calculated using the balloon altitudes for measured temperatures between $0.5^{\circ}$ and $-0.5^{\circ} \mathrm{C}$ is $4787 \pm$ $144 \mathrm{~m}$ for the over 1000 quality-controlled soundings obtained during the project. The tropopause (defined by an abrupt change in lapse rate) is located near $15-\mathrm{km}$ altitude. Comparisons of the site-averaged mixing ratio profiles are complicated by differences in biases among the various types of humidity sensors (Loehrer et al. 1996; Elliot et al. 2002). Sobel et al. (2004) examined the daily intersite variability using perturbations from site averages that take into account the differences in biases among the sites. They found that the standard deviation of $\mathrm{RH}$ perturbations was $\sim 2 \%$, which is much smaller than RH perturbation day-to-day variability. The magnitude and vertical structure of variability within the sounding array are similar to those for the Tropical Ocean and Global Atmosphere (TOGA) Coupled Ocean-Atmosphere Response Experiment (COARE) and the South China Sea Monsoon Experiment (SCSMEX) arrays (Mapes et al. 2003). Plots of equivalent potential temperature $\theta_{e}$ and saturated equivalent potential temperature $\theta_{e s}$ (Fig. 8), calculated using Bolton's formula (Bolton 1980), show that for mean conditions during KWAJEX the atmosphere exhibited potential instability for the layer from the surface to $4.5-\mathrm{km}$ altitude.

The wind profiles in Fig. 9 illustrate the weak shear within the layer of easterly winds from the surface to $350 \mathrm{hPa}$. Among the sites, the lower-tropospheric winds back slightly from east-southeast at the more northern sites of Roi and Kwajalein to the almost pure easterly winds for the Brown, Lae, and Woja sites. Maximum average wind speeds are $8 \mathrm{~m} \mathrm{~s}^{-1}$ near $650 \mathrm{hPa}$ at Woja and decrease to $7 \mathrm{~m} \mathrm{~s}^{-1}$ as one moves north toward Roi. Above $350 \mathrm{hPa}$, winds veer to westerly at $150 \mathrm{hPa}$ and then back to easterly at $100 \mathrm{hPa}$. As one moves south from Roi to Woja, the $150-\mathrm{hPa}$ winds veer from west-southwest to west-northwest, consistent with a progressively stronger influence from the ITCZ upperlevel outflow as one moves south (Sobel et al. 2004).

Calculations of apparent heat source $Q_{1}$ and apparent moisture sink $Q_{2}$ in budget studies (e.g., Lin and Johnson 1996) provide independent means of evaluating areal surface precipitation and latent heating profiles estimated by satellite- and surface-based instruments. The closed upper-air sounding array formed by stations at Kwajalein, Roi-Namur, Lae, Woja, and the Brown is being employed as input to a budget study in progress (M. Zhang 2002, personal communication).

\section{d. Surface point rainfall measurements}

To complement the areal radar-rainfall estimates, several types of point rainfall measurements were obtained during KWAJEX (Table 11). The nominal GV rain gauge network (Schumacher and Houze 2000) was enhanced with additional tipping-bucket gauges on Roi-Namur and Kwajalein Islands. Several types of disdrometers were deployed to obtain information on the details of the near-surface drop size distribution (DSD). The disdrometer deployments yielded limited usable data for a variety of reasons. There were persistent problems with the $2 \mathrm{D}$ video disdrometer on Kwajalein and with the piezoelectric disdrometers. Although the decreased sensitivity of the Joss-Waldvogel disdrometer to small drops under conditions of wind and/or noise is well documented (Joss and Gori 1976), the practical implications were not fully appreciated.

TABLE 8. NOAA Aeronomy Laboratory profiler instrumentation on Legan Island.

\begin{tabular}{lc}
\hline \hline \multicolumn{1}{c}{ System } & Measurement \\
\hline 915-GHz profiler & Vertical profiles of horizontal winds, \\
& $Z$ and $V_{r}$ \\
S-band profiler & Vertical profiles of $Z$ and $V_{r}$ \\
\hline
\end{tabular}


TABLE 9. Summary of upper-air sounding operations during KWAJEX. Upper-air sounding system types included a Vaisala, Inc., GPS system, VIZ, Inc., GPS system, and MSS non-GPS system.

\begin{tabular}{|c|c|c|c|c|}
\hline Station & Sonde type & Total launches & Successful launches & $\begin{array}{l}\text { Primary reason for } \\
\text { failed/incomplete launches }\end{array}$ \\
\hline Kwajalein & MSS & 245 & 191 & Early termination \\
\hline Lae & VIZ & 241 & 222 & No predominant reason \\
\hline Meck & MSS & 63 & 18 & Sonde or system failure \\
\hline Brown & Vaisala & 324 & 239 & Total or intermittent loss of wind data \\
\hline Roi & MSS & 238 & 208 & Early termination \\
\hline Woja & VIZ & 197 & 190 & No predominant reason \\
\hline
\end{tabular}

Figure 10 shows average drop spectra using nearly identical Joss-Waldvogel disdrometers obtained on three islands during KWAJEX. The number of drops smaller than $1 \mathrm{~mm}$ measured varies widely from very few on Legan (Fig. 10a), a few more on Meck (Fig. 10c), to more on Kwajalein (Fig. 10b). The disdrometers were located within $50 \mathrm{~km}$ of each other and sampled rain events in the same season. Although the rainfall samples are not expected to be identical, the wide variation in small drop concentrations observed in the data is meteorologically unlikely and is more likely related to either individual instrument problems or siting problems.

Further investigation revealed that the primary problem was the instrument siting. The instrument at Legan was subject to both wind and noise from a nearby diesel generator. The instrument at Kwajalein was influenced by wind and a nearby air conditioner. The conditions at Meck were undocumented, but one can surmise that wind and/or noise contributed to the loss of smaller drops by comparing its data with those from the other sites. To test the hypothesis that siting was the primary problem, the Joss-Waldvogel disdrometer that was on Kwajalein Island during KWAJEX was returned to Kwajalein in the summer of 2000 and placed in a quiet, wind-sheltered area. The resulting DSD (Fig. 10d) shows more small drops than any of the KWAJEX datasets and reveals a nearly exponential distribution for the average drop spectra corresponding to rain rates $<1 \mathrm{~mm} \mathrm{~h}^{-1}$, where potential underestimation of small drops related to instrument dead time has the least influence (Joss and Gori 1976; Sheppard and Joe 1994). In light of the findings of the sensitivity of the observed DSD to wind and noise, Aeromet, Inc., developed a low-wind-resistance instrument stand and placed the disdrometer within a circular hedge to minimize loss of small drops by wind effects. Disdrometer measurements within the improved shelter have been ongoing at Kwajalein as part of the TRMM GV site activities.

\section{Climatological setting of KWAJEX}

The characteristics of radar echo coverage within a $240-\mathrm{km}$ radius of Kwajalein during the rainy seasons in 1999, 2000, and 2001 were examined to provide a climatological context for the sample of precipitating clouds observed in KWAJEX. Figure 11 compares total monthly precipitating echo $>20 \mathrm{dBZ}$ for the rainyseason months ${ }^{3}$ of 1999, 2000, and 2001. In comparison with the best-guess radar calibration (appendix A), rain echo areas for best-guess $Z+2 \mathrm{~dB}$ were up to $136 \%$ greater and for $-2 \mathrm{~dB}$ were down to $73 \%$ lower for a given month. The KWAJEX year (1999) had somewhat less rain than the other years. The most significant differences in monthly precipitation relative to 1999 were for August 2000 (210\%), December 2000 (225\%), and September 2001 (154\%).

The increase in Kwajalein S-band radar echo area $>20 \mathrm{dBZ}$ in July-December 2000 and 2001 when compared with July-December 1999 (Fig. 11) is consistent with the weakening of the regional cold SST anomaly in the summer of 2000 as compared with the summer of 1999 and its replacement by a warm SST anomaly in the summer of 2001 (Fig. 12). The SST anomaly signatures

\footnotetext{
${ }^{3}$ Radar data availability constrained our examination of the 1999 rainy season to begin in the latter part of July 1999. Depending on how it is defined, the Kwajalein rainy season begins in May or June. For this analysis, we used the months of July-December so that we would have comparable periods for all three years.
}

TABLE 10. Suite of instruments for boundary layer measurements deployed on Meck Island.

\begin{tabular}{|c|c|}
\hline System & Measurement \\
\hline University of Virginia tethered sonde & Profile of wind, temperature, and $\mathrm{RH}$ from the surface to $1.5 \mathrm{~km}$ \\
\hline University of Virginia $10-\mathrm{m}$ meteorological tower & Boundary layer energy fluxes and microclimate measurements \\
\hline University of Virginia sodar & $\begin{array}{l}\text { Horizontal wind speed and direction, turbulence intensities, thermal } \\
\text { structure, and mixing depth heights }\end{array}$ \\
\hline $\begin{array}{l}\text { Florida State University pyranometer, pyrgeometer, and } \\
\text { pyrradiometer }\end{array}$ & Longwave radiation and albedo \\
\hline
\end{tabular}




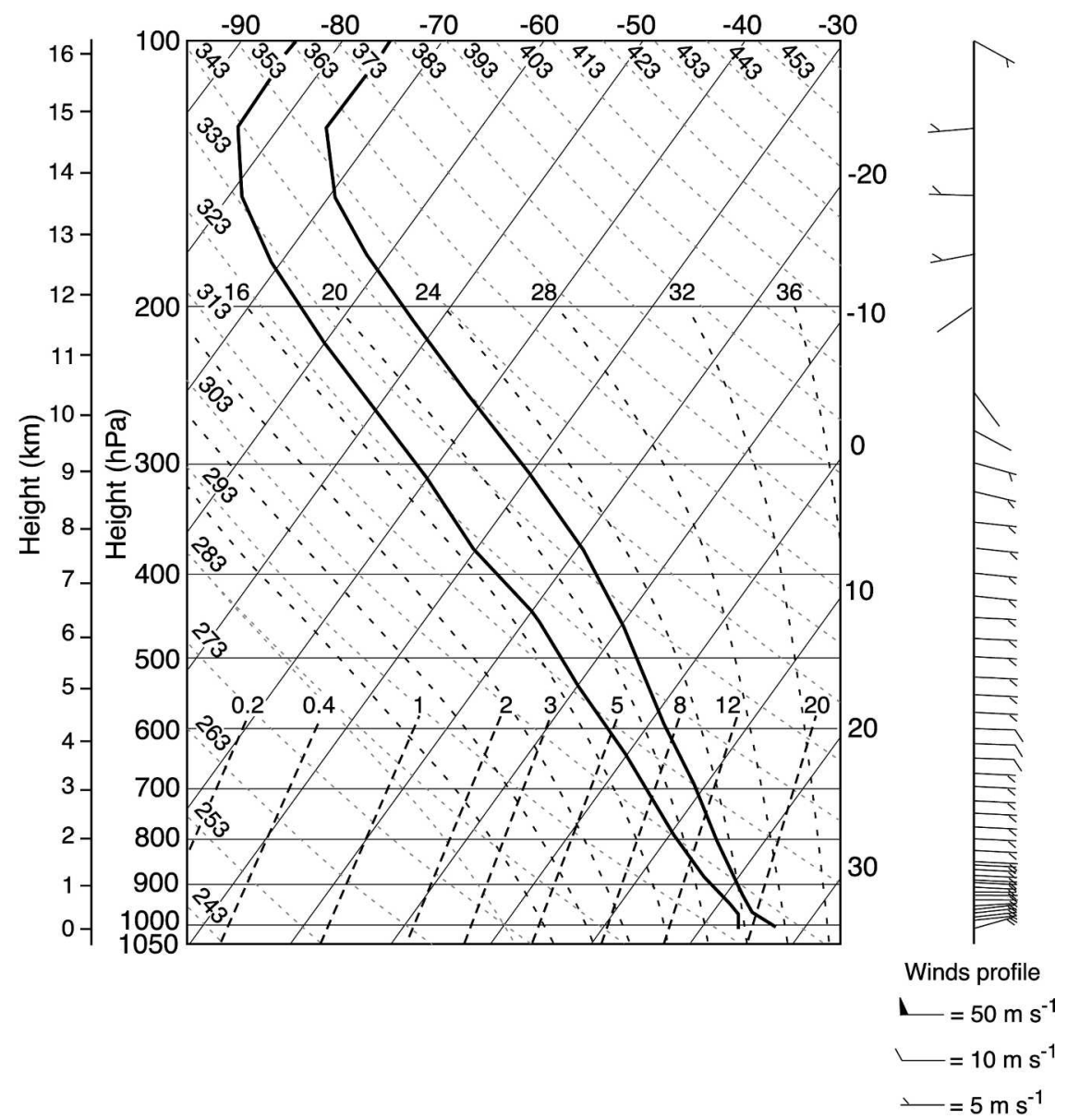

FIG. 7. KWAJEX-project-averaged sounding based on quality-controlled soundings from the Brown and Kwajalein, Roi-Namur, Lae, and Woja Islands (Sobel et al. 2004).

of the interannual El Niño-Southern Oscillation (ENSO) phases are not as strong in the Kwajalein region as in the eastern and central Pacific and can be in the opposite direction (U.S. CLIVAR Pan American Implementation Panel 2002). According to the Niño-3.4 index, which is based on SST anomalies in the region of $5^{\circ} \mathrm{S}-5^{\circ} \mathrm{N}, 120^{\circ}-170^{\circ} \mathrm{W}$, the KWAJEX period corresponded to a cold phase of ENSO (Fig. 13). The regional sea surface temperatures $\left(7^{\circ}-11^{\circ} \mathrm{N}, 163^{\circ}-173^{\circ} \mathrm{E}\right)$ during the KWAJEX period in July-September 1999 are below average $\left(-0.3^{\circ}\right.$ to $\left.-0.45^{\circ} \mathrm{C}\right)$ but not as far below average $\left(-0.7^{\circ} \mathrm{C}\right)$ as during the peak in the ENSO warm phase in early 1998 (Fig. 12).

Figure 14 shows the frequency distribution of radar echo coverage $>20 \mathrm{~dB} Z$ within a $240-\mathrm{km}$ radius of Kwajalein on a semilog plot for the 3-yr rainy-season dataset. To obtain this distribution, data from the Kwajalein S-band $360^{\circ}$ low-elevation-angle surveillance scans (appendix A) were interpolated to a $4 \mathrm{~km} \times 4 \mathrm{~km}$ Cartesian grid to yield statistics of a radar echo area of $>20 \mathrm{dBZ}$ for the region of $>17-\mathrm{km}$ range and $<240-\mathrm{km}$ range (within a $17-\mathrm{km}$ range, ground clutter contami-

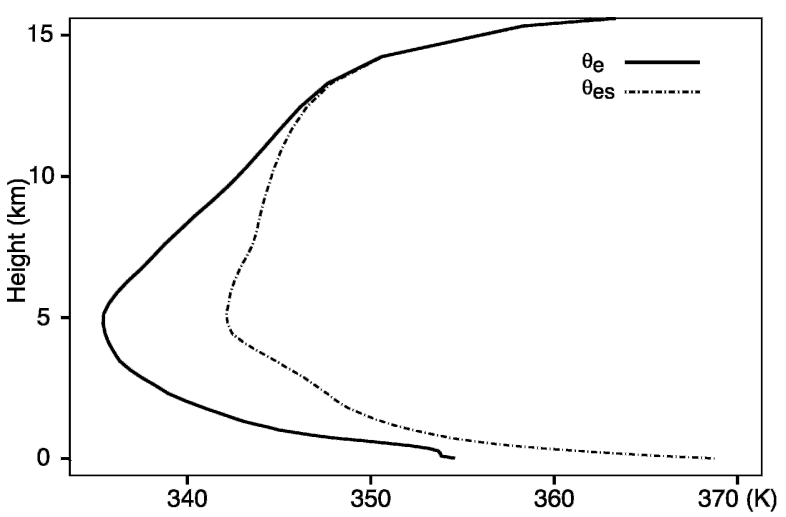

FIG. 8. KWAJEX project mean profiles of $\theta_{e}$ and $\theta_{e s}$, utilizing quality-controlled upper-air soundings from the Brown and RoiNamur, Kwajalein, Lae, and Woja Islands. See Sobel et al. (2004) for details of the quality-control procedure. 


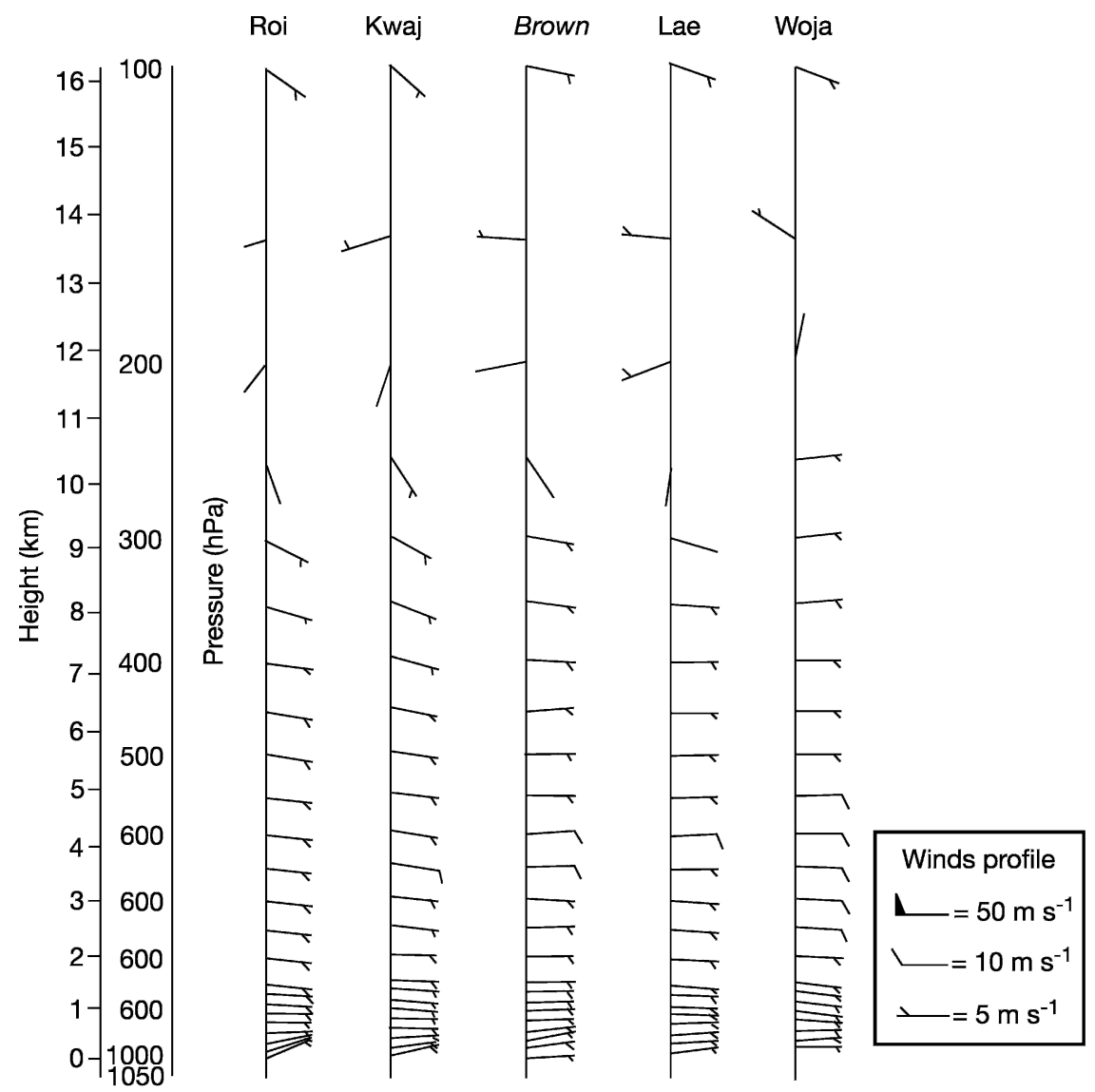

FIG. 9. Site-averaged wind profiles for the five KWAJEX sounding sites. For presentation purposes, wind speeds are rounded to the nearest $2.5 \mathrm{~m} \mathrm{~s}^{-1}$.

nates the data). The surveillance scans cover an area roughly 2.4 times that of the volume scans used for quantitative rain mapping and hence permit examination of a larger sampling region. The echo area of $>20$ $\mathrm{dBZ}$ includes both contiguous and noncontiguous echoes. The echo area of $>20 \mathrm{dBZ}$ from each of the five surveillance scans per hour are averaged to obtain the hourly averaged values. A threshold of $20 \mathrm{dBZ}$, corresponding to $\sim 0.7 \mathrm{~mm} \mathrm{~h}^{-1}$ for a $4 \mathrm{~km} \times 4 \mathrm{~km}$ pixel, is used to delineate rainy echo in the surveillance scan data. For the KWAJEX period, the hourly areal average rain rates for the region within a $150-\mathrm{km}$ radius derived from the UW quantitative rain maps on the Goddard Space Flight Center (GSFC) Distributed Active Archive Center (DAAC; Houze et al. 2004) are strongly correlated $\left(r^{2}=0.94\right)$ with the hourly average echo area of $>20 \mathrm{~dB} Z$ within $150 \mathrm{~km}$ obtained from the surveillance scans. Such high correlations between the echo area and rain volume were first noted by Byers (1948).

The area coverage distribution in Fig. 14 is roughly lognormal but has a smaller frequency of areas $>9000$ $\mathrm{km}^{2}$ than a lognormal distribution would predict (i.e., a truncated lognormal distribution). This deviation from lognormal results either from a natural upper limit on the size attainable by radar echoes in this region, or it reflects the underestimation of large echo areas that extend beyond the radar domain. Previous studies have also indicated a truncated lognormal distribution of echo areas for the tropical Atlantic Ocean (Houze and Cheng 1977; López 1977) and of contiguous IR cold cloudiness over Indonesia and the west Pacific warm pool (Williams and Houze 1987; Mapes and Houze 1992). These other studies examined larger domains

TABLE 11. Disdrometers and rain gauges deployed during KWAJEX included Distromet, Inc., Joss-Waldvogel disdrometers, Joanneum Research 2D video disdrometers, Johns Hopkins University (JHU)/Applied Physics Laboratory piezoelectric disdrometers, and Qualimetrics, Inc., tipping-bucket rain gauges.

\begin{tabular}{ll}
\hline \hline \multicolumn{1}{c}{ System } & \multicolumn{1}{c}{ Locations } \\
\hline Joss-Waldvogel disdrometer & Kwajalein, Legan, Meck \\
2D video disdrometer & Kwajalein, Legan \\
JHU/APL piezoelectric & Kwajalein, Legan, Meck, \\
disdrometer & Roi-Namur, Woja, Lae, Brown \\
Tipping-bucket rain gauge & Kwajalein, Legan, Meck, \\
& Roi-Namur, Woja, Lae, \\
& Gellinam, Illeginni, Gagan \\
\hline
\end{tabular}



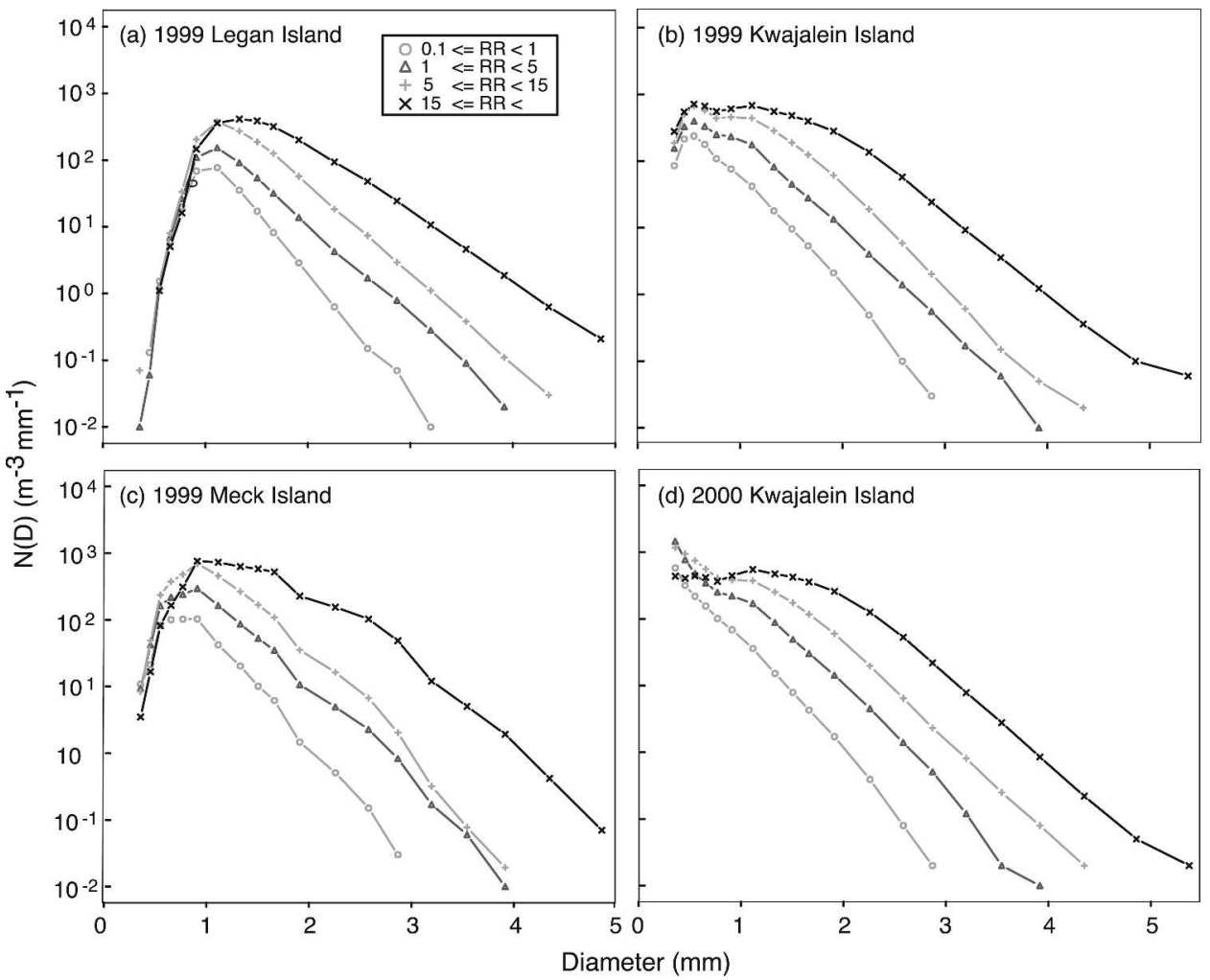

FIG. 10. Average DSD grouped by 10-min accumulated rain-rate categories: $0.1-1,1-5,5-15$, and $>15$ $\mathrm{mm} \mathrm{h} \mathrm{h}^{-1}$, as observed by Joss-Waldvogel disdrometers on (a) Legan Island, 2 Jul-30 Nov 1999; (b) Kwajalein Island, 14 Jul-29 Aug 1999; (c) Meck Island, 17 Aug-8 Sep 1999; and (d) Kwajalein Island, 30 Jun-31 Aug 2000. (Legan data are provided through the courtesy of C. Williams of CIRES; Meck data are provided through the courtesy of A. Tokay of GSFC.)

than the one examined here. A comparison of total area (as in Fig. 14 and Table 12) to contiguous area statistics will differ most for small sizes; at larger sizes most of the echo area is within the contiguous regions.

The statistics of the echo area coverage distribution are described in terms of cumulative area and cumulative frequency quartiles in Table 12. Examination of the cumulative area quartiles in Table 12 illustrates that, on average, the KWAJEX radar echoes tended to be slightly smaller in area than those occurring later in 1999. Comparison among the July-December rainy seasons $^{3}$ for 1999,2000 , and 2001 shows that the 2000 rainy season had the largest integrated area totals and the largest radar echo areas for a given cumulative percentage (Table 12). Seasonal rainfall is strongly weighted by the few largest radar echoes. For the 3-yr Kwajalein rainy-season sample of 12135 hourly precipitating echo coverage averages, $50 \%$ of the hours contain echo areas $<\sim 6400 \mathrm{~km}^{2}$. These echoes contribute $\sim 12 \%$ of the total rain area. In contrast, $50 \%$ of the rainy area is contributed by echoes with echo coverage of $>\sim 20000 \mathrm{~km}^{2}$, which occur in only $16 \%$ of the sampled hours. The diurnal cycle of precipitation area is also strongly influenced by the relatively few large echoes that preferentially occur in the early morning hours, peak near dawn, and tend to dissipate before noon (Fig. 15), and is similar to the diurnal behavior of large cloud systems over the west Pacific warm pool (Chen et al. 1996; Chen and Houze 1997). The midaf-
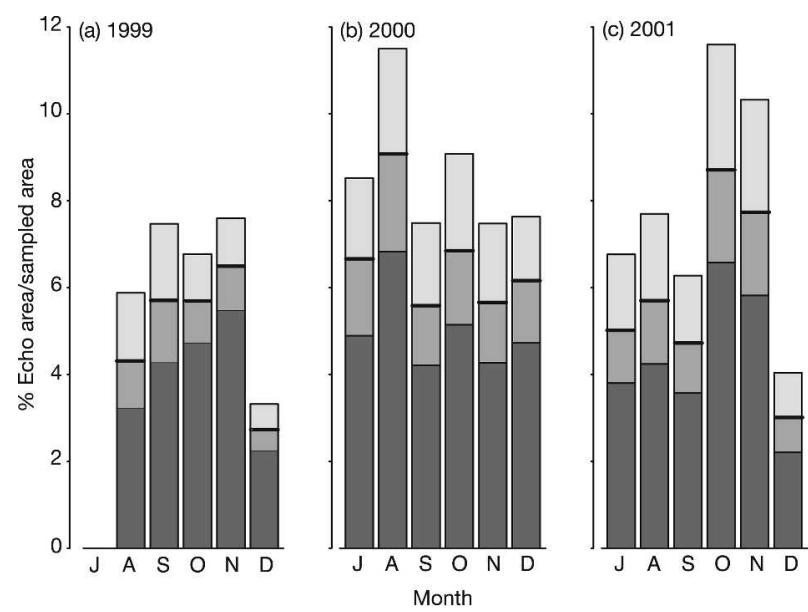

FIG. 11. Total monthly echo area $>20 \mathrm{dBZ}$ as a percentage of a $240-\mathrm{km}$-radius sampled area (line on top of medium gray bars). Impact of radar calibration uncertainty on area totals is indicated by top of light gray bar $(+2 \mathrm{~dB})$ and top of dark gray bar $(-2 \mathrm{~dB})$. 


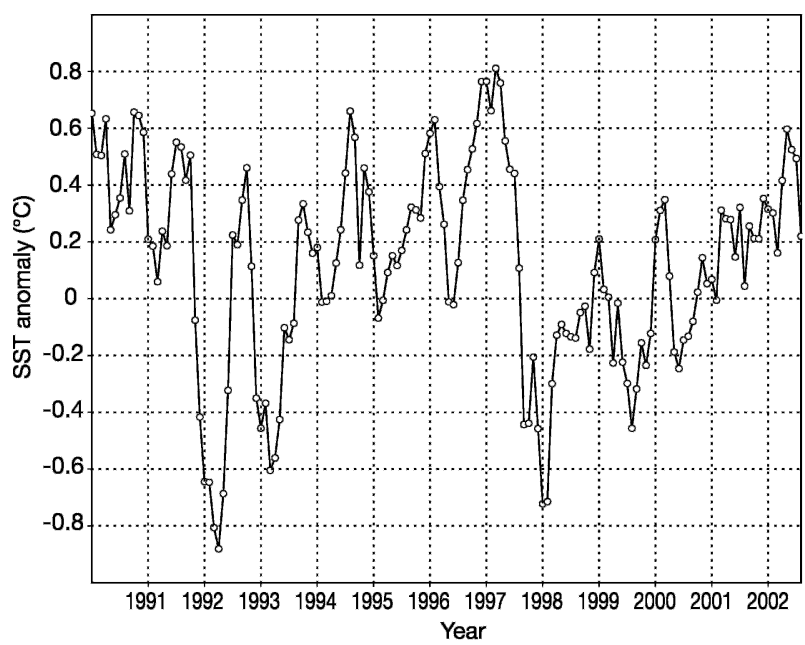

FIG. 12. Monthly average Reynolds sea surface temperature anomaly (average based on data from 1981 to the present) for the region $7^{\circ}-11^{\circ} \mathrm{N}, 163^{\circ}-173^{\circ} \mathrm{E}$ centered on Kwajalein, from Jan 1990 to Aug 2002. (Plot is provided through the courtesy of A. Sobel of Columbia University.)

ternoon peak in the average diurnal cycle (Fig. 15b) is weaker than the early morning peak and is associated with a trend of increasing frequency within the top three size quartiles. Radar echoes in the third quartile occur with roughly equal frequency from 0600 to 0800 LT and are least likely to occur near noon. Rain areas with radar echo coverage within the first frequency quartile $\left(<2272 \mathrm{~km}^{2}\right)$ also exhibit a diurnal cycle and occur most frequently between 0900 and 1400 LT and peak at noon, suggesting an association between small rain areas and shortwave radiative forcing. However, whether the shortwave forcing acts in terms of enhancement of smaller echoes or suppression of larger echoes is not discernable from these data. The single-peak diurnal behavior of the small radar echoes differs from that observed for small cold cloud systems over the western Pacific warm pool, which had both afternoon and predawn peaks (Chen and Houze 1997). As suggested by Chen and Houze (1997), the predawn maximum of small clouds in the case of TOGA COARE was probably a spin-off of the high frequency of large systems occurring at that time. Large-scale conditions fa-

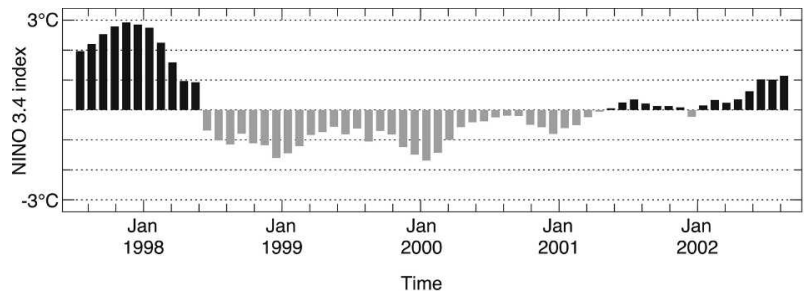

FIG. 13. Plot of Niño-3.4 index from 1 Jul 1997 to 1 Sep 2002, using Web-based data (obtained online at iri.columbia.edu/ climate/ENSO/).

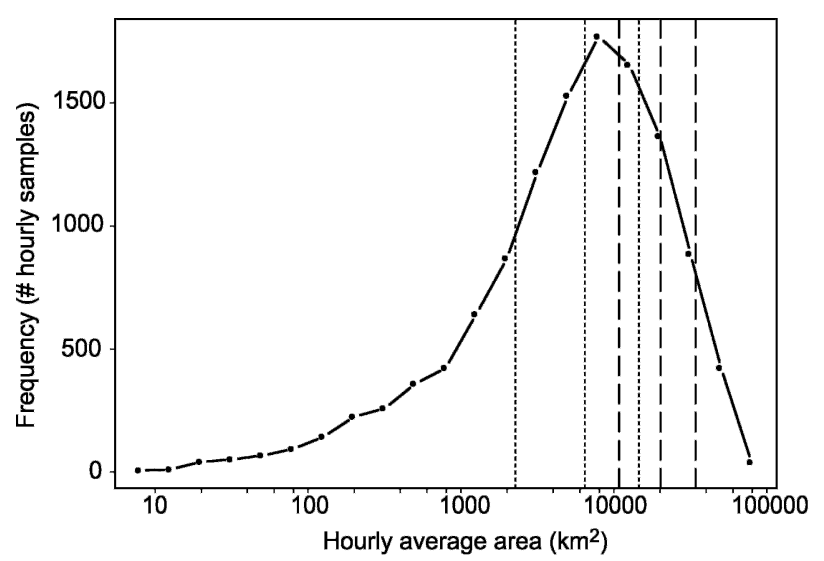

FIG. 14. Histogram of hourly average echo area $>20 \mathrm{dBZ}$ within a $240-\mathrm{km}$ radius of Kwajalein for a 3-yr rainy-season dataset [each hourly average is based on five samples, and there are 12135 hourly average samples (Table 12)]. The echo area includes all $16-\mathrm{km}^{2}$ pixels $>20 \mathrm{dBZ}$ within the domain, including contiguous and noncontiguous echoes. Short-dashed lines indicate the echo area corresponding to cumulative frequency quartiles at $25 \%$, $50 \%$, and $75 \%$. Long-dashed lines indicate the echo area corresponding to cumulative area quartiles at $25 \%, 50 \%$, and $75 \%$.

voring large organized precipitating cloud systems can favor the small ones as well. Cold pools from the large systems can trigger small convection because the large systems have a "gregarious" effect on account of the environmental upward motion compensating for the broad mesoscale downdrafts of the large systems (Mapes 1993; Mapes and Houze 1995). An overall less

TABLE 12. Hourly average radar echo areas $\left(\mathrm{km}^{2}\right)$ for a 240 $\mathrm{km}$-radius domain surrounding Kwajalein corresponding to quartiles computed from distributions of cumulative area and cumulative frequency.

\begin{tabular}{|c|c|c|c|c|}
\hline \multicolumn{5}{|c|}{ Cumulative area } \\
\hline & $25 \%$ & $50 \%$ & $75 \%$ & $\begin{array}{c}\text { Total } \\
\text { echo area }\end{array}$ \\
\hline a. KWAJEX & 7072 & 14138 & 24469 & 9634599 \\
\hline $\begin{array}{l}\text { b. } 23 \text { Jul } 1999- \\
31 \text { Dec } 1999\end{array}$ & 8328 & 16816 & 28664 & 33307996 \\
\hline $\begin{array}{l}\text { c. } 1 \text { Jul 2000- } \\
31 \text { Dec } 2000\end{array}$ & 12188 & 22310 & 36984 & 49505268 \\
\hline $\begin{array}{l}\text { d. } 1 \text { Jul 2001- } \\
31 \text { Dec } 2001\end{array}$ & 11557 & 20150 & 34761 & 45240344 \\
\hline$b+c+d$ & 10774 & 20134 & 34102 & 128053608 \\
\hline \multicolumn{5}{|c|}{ Cumulative frequency } \\
\hline & $25 \%$ & $50 \%$ & $75 \%$ & $\begin{array}{l}\text { Total No. } \\
\text { samples }\end{array}$ \\
\hline e. KWAJEX & 1864 & 5038 & 10126 & 1238 \\
\hline $\begin{array}{l}\text { f. } 23 \text { Jul 1999- } \\
31 \text { Dec } 1999\end{array}$ & 2031 & 5418 & 11326 & 3780 \\
\hline $\begin{array}{l}\text { g. } 1 \text { Jul 2000- } \\
31 \text { Dec } 2000\end{array}$ & 2703 & 7732 & 16951 & 4124 \\
\hline $\begin{array}{l}\text { h. } 1 \text { Jul 2001- } \\
31 \text { Dec 2001 }\end{array}$ & 2064 & 6419 & 14752 & 4231 \\
\hline$f+g+h$ & 2272 & 6436 & 14548 & 12135 \\
\hline
\end{tabular}



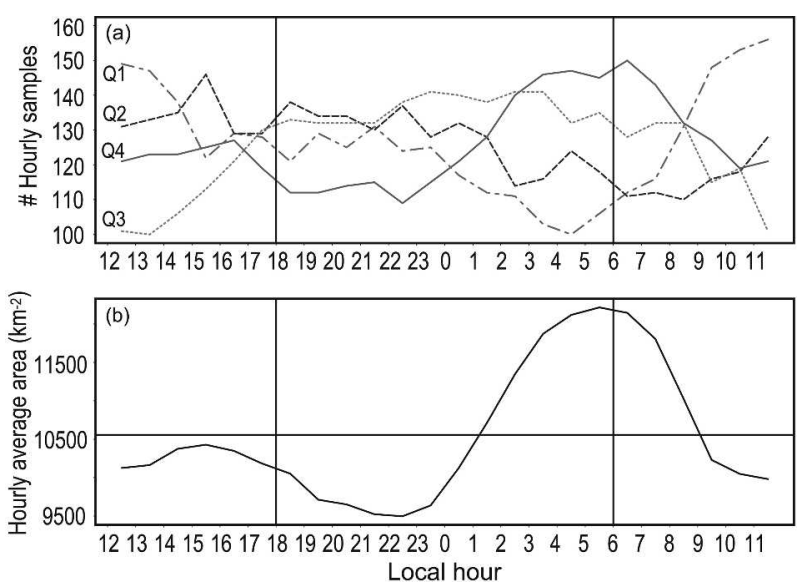

FIG. 15. (a) Distribution of radar echo within a 240-km-radius domain by time of day for each cumulative-frequency quartile in Table 12. Label Q1 denotes echo areas $<2272 \mathrm{~km}^{2}$, Q2 is for 2272 $\mathrm{km}^{2}<$ echo area $<6438 \mathrm{~km}^{2}, \mathrm{Q} 3$ is for $6438 \mathrm{~km}^{2}<$ echo area $<$ $14548 \mathrm{~km}^{2}$, and Q4 is for echo areas $>14548 \mathrm{~km}^{2}$. (b) Diurnal cycle of echo area within a $240-\mathrm{km}$-radius domain. The total variation between max and $\min \left(2724 \mathrm{~km}^{2}\right)$ values represents $26 \%$ of the average value of $10550 \mathrm{~km}^{2}$. Both (a) and (b) are based on a 3 -yr rainy-season dataset.

frequent occurrence of large systems near Kwajalein in comparison with the TOGA COARE region farther south might then be expected to mute the predawn maximum of small precipitating cloud entities. The total diurnal cycle (Fig. 15b) results for Kwajalein based on ground-based radar data during the rainy season are similar to the diurnal cycle peak for the northwest tropical Pacific precipitation features with ice scattering (Nesbitt and Zipser 2003, see their Fig. 14) using 2-h binning of a 3-yr TRMM satellite dataset gridded to $10^{\circ} \times 10^{\circ}$.

\section{Precipitating cloud population sampled during KWAJEX}

Figure 16 shows the time series of the rainy echo area within a $240-\mathrm{km}$ radius of Kwajalein. The time series of hourly areal average rain rate derived from the Kwajalein radar is shown in Fig. 17. The time series of Fig. 17 is based only on the radar data within $150 \mathrm{~km}$, which is the range within which the radar reflectivity field can reliably be converted to rain maps and within which elevation-angle sequence scans were interpolated to a three-dimensional Cartesian grid for vertical structure analysis. Rainfall map products ${ }^{4}$ containing estimates of surface rainfall, including instantaneous rain rates and monthly rain accumulations, were produced for the KWAJEX period using data from the Kwajalein S-

\footnotetext{
${ }^{4}$ The Houze et al. (2004) rain maps utilize a minimum threshold of $\sim 0 \mathrm{~dB} Z$ for a rainy pixel corresponding to a minimum rain rate of $\sim 0.02 \mathrm{~mm} \mathrm{~h}^{-1}$.
}

band radar following the procedures developed by the University of Washington for the Kwajalein GV site (Houze et al. 2004). The conditional mean rain rate (i.e., average in areas where it is raining) is $2.1 \mathrm{~mm} \mathrm{~h}^{-1}$ $\pm 0.96 \mathrm{~mm} \mathrm{~h}^{-1}$ for $4-\mathrm{km}^{2}$ pixels. The areal average mean rain rate (including areas where it is not raining) is $0.22 \mathrm{~mm} \mathrm{~h}^{-1}$, which is equivalent to $5.3 \mathrm{~mm} \mathrm{day}^{-1}$. The frequency distribution of hourly areal rain rate is approximately lognormal, as it is in most places in the world. The shape of the hourly rainfall rate distribution for KWAJEX (not shown) can be described in terms of the mean and standard deviation of $\log _{10}$ of the hourly areal rain rate, whose distribution is approximately Gaussian. The mean of $\log _{10}$ of the hourly areal rain rate is -0.99 , and the standard deviation is 0.61 . The differences between the rainfall time series within a $150-\mathrm{km}$ radius (Fig. 17) and the rainfall echo area time series within a $240-\mathrm{km}$ radius (Fig. 16) are primarily due to differences in the sampling region. The time series of rainfall echo area $>20 \mathrm{dBZ}$ for the 150$\mathrm{km}$ radius (not shown) is qualitatively nearly identical to Fig. 17.

Superimposed on the time series in Figs. 16 and 17 are dots indicating the start times of KWAJEX aircraft missions. Within the constraint that two of the aircraft did not fly at night, most of the large rain areas were sampled near their peaks. The aircraft flights appear to have covered a sample of precipitating clouds typical of the Kwajalein region. The largest precipitation areas occurred on 25-26 July, 11-12 August, and 2-3 September. The large-scale meteorological conditions associated with these three events are discussed in detail in Sobel et al. (2004). Twenty-six of the 39 aircraft missions sampled smaller echoes with peak rainfall areas occupying $<10 \%$ of the region within a $240-\mathrm{km}$ radius (i.e., $<18000 \mathrm{~km}^{2}$ ). As discussed above, fewer large precipitating cloud systems occurred during KWAJEX than during the same period of subsequent years; however, flight data were obtained on all the days on which the larger precipitation areas occurred.

\section{The case of 11-12 August 1999}

The best-sampled large mesoscale precipitation system during KWAJEX occurred on 11-12 August 1999. The 11-12 August convective system was associated with the interaction between a westward-propagating mixed Rossby gravity wave and an eastward-propagating Kelvin wave that crossed paths near Kwajalein (Sobel et al. 2004). At 1200 UTC 11 August 1999, nearsurface winds varied in direction across the sounding array but were consistently easterly at $500 \mathrm{hPa}$ and northwesterly at $150 \mathrm{hPa}$. Digital photos obtained at 2000 UTC 11 August 1999 as the mesoscale precipitation system approached Kwajalein (Fig. 18) show overlying cirrus and shallow cumulus clouds on the edges of the system being replaced by the deeper cumu- 


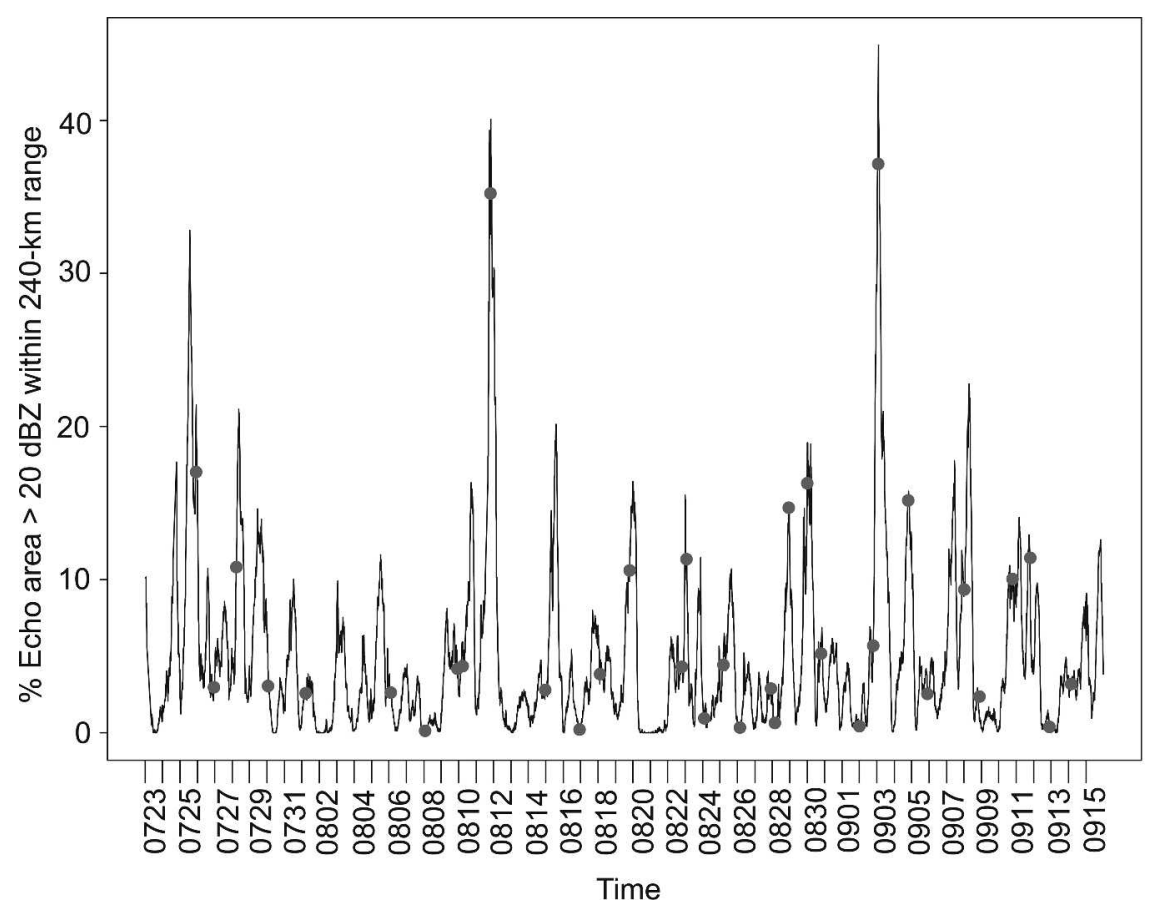

FIG. 16. Echo area $>20 \mathrm{dBZ}$ within a $240-\mathrm{km}$ range of Kwajalein based on $1^{\circ}$-elevation-angle surveillance scan data. Start times of aircraft missions are indicated by dots.

lonimbus within which the main radar echoes were located. Figure 19 shows the surveillance-scan radar echo pattern in the Kwajalein region at 2214 UTC 11 August 1999, about $45 \mathrm{~min}$ prior to the peak areal rainfall within a 150-km radius of Kwajalein (Fig. 17). The primary echo was over $400 \mathrm{~km}$ in horizontal scale and extended beyond $150-\mathrm{km}$ range. Overlapping white circles in Fig. 19 indicate the region of dual-Doppler

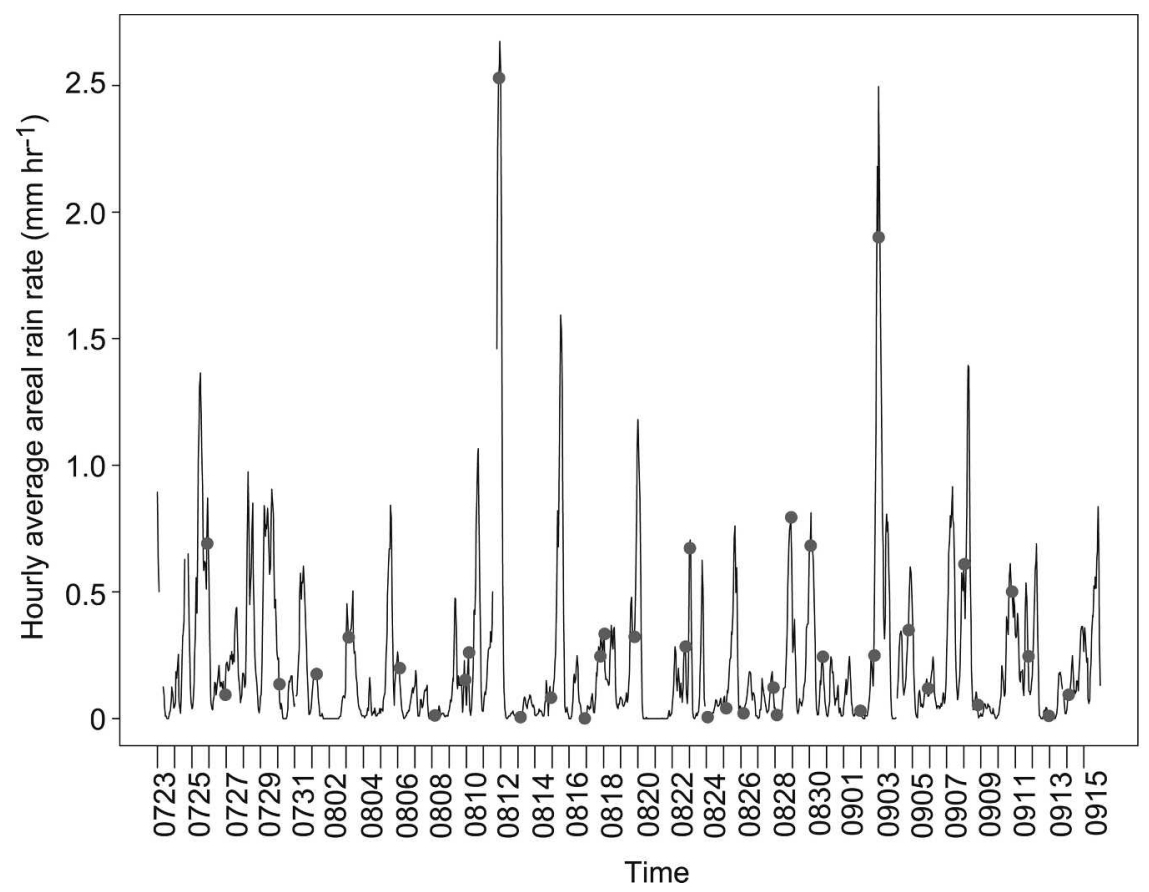

FIG. 17. Hourly average rain rate for a 150-km-radius region centered on Kwajalein computed from UW rain maps on the Goddard DAAC (Houze et al. 2004). Start times of aircraft missions are indicated by dots. 

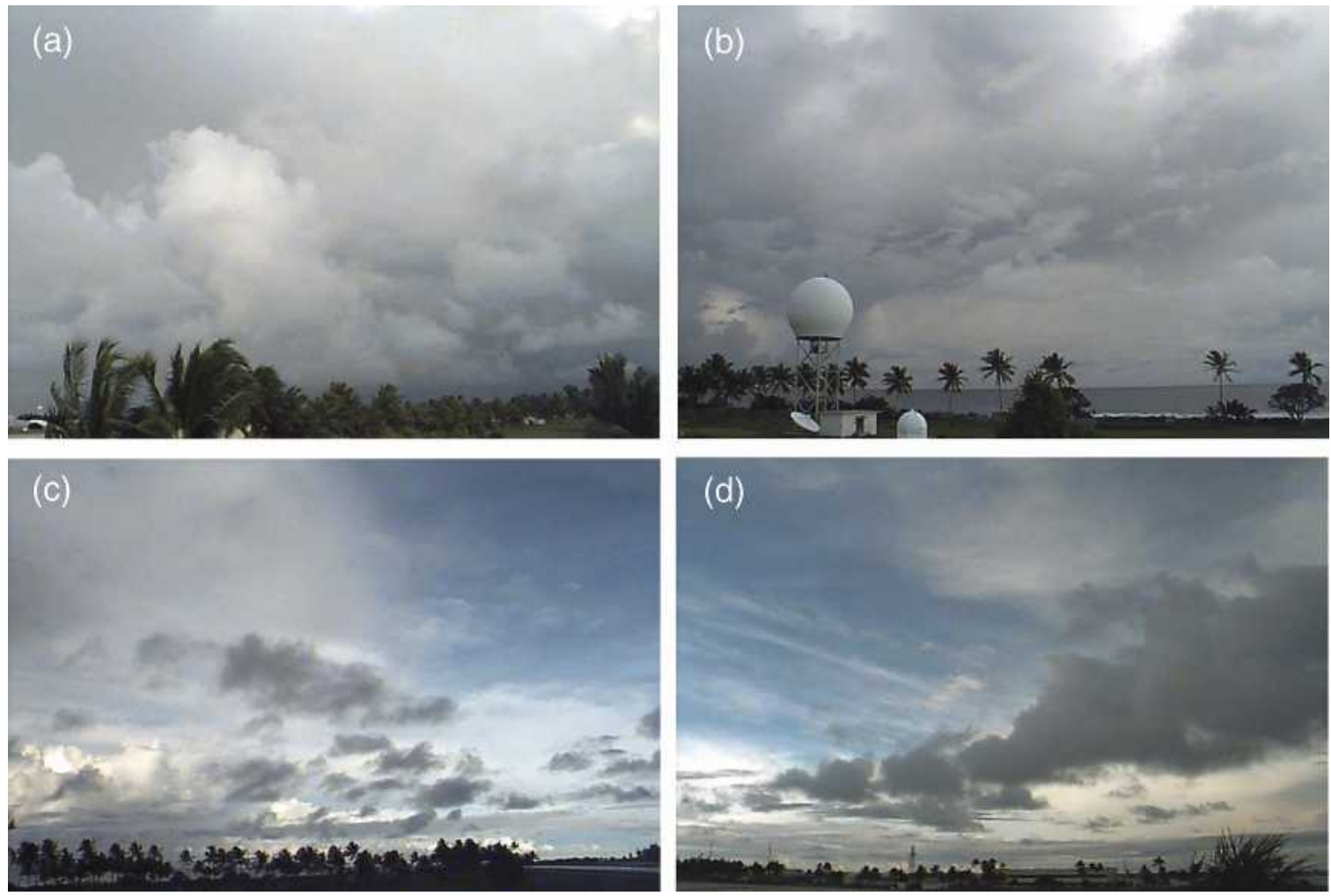

FIG. 18. Clouds observed from the roof of the Kwajalein weather station at 2000 UTC (0800 LT) 11 Aug 2000. Camera directions are relative to north: (a) $60^{\circ}$, (b) $150^{\circ}$, (c) $240^{\circ}$, and (d) $330^{\circ}$.

coverage by the Kwajalein and ship radars. The flight track of the NASA DC-8 (purple line) passed through the east dual-Doppler lobe. The UW Convair flew parallel to the DC-8 track. A close up of the flight tracks and the radar echo pattern is shown in Fig. 20. In situ microphysics data were obtained along these flight tracks. Figures $20 \mathrm{~b}-\mathrm{d}$ show the subset of downwardlooking AMPR radiometer data on board the DC-8 corresponding to the swath width of the ARMAR radar aboard the DC- $8 .{ }^{5}$

\section{a. Ground-based radar and aircraft remote sensing}

Figure 20 shows the variation in horizontal spatial patterns among near-surface radar reflectivity and passive microwave signatures at different frequencies. As expected, the lower-frequency radiometer channels at 10.7 and $19 \mathrm{GHz}$ exhibit patterns most similar to that of the low-level radar echo. These channels are most sensitive to the emission of the vertical column of rain, and higher brightness temperatures are associated with higher reflectivities and surface rainfall. The $85-\mathrm{GHz}$ data map the pattern of column ice scattering. Lower brightness temperatures are associated with more scat-

\footnotetext{
${ }^{5}$ AMPR scans $\pm 45^{\circ}$ cross-track as compared with $\pm 20^{\circ}$ crosstrack for ARMAR.
}

tering and more column-integrated ice. Local minima in $85-\mathrm{GHz} T_{b}$ are offset in position from the regions of high reflectivity at low levels. Other flight tracks show a similar lack of spatial correlation between $85-\mathrm{GHz}$ ice scattering and strong low-level reflectivities. This behavior differs significantly from midlatitude continental convection observed by Heymsfield and Fulton (1988) that showed a much closer spatial correlation between ice scattering aloft and high reflectivity at low levels. Because vertical wind shear is weak near Kwajalein (section 3c), the cause of the offset is not wind shear. Possibly the poor correlation of low-level reflectivity and $85-\mathrm{GHz}$ ice scattering is related to the weaker updrafts characteristic of oceanic convection as compared with continental convection (Lucas et al. 1994). The $85-\mathrm{GHz}$ ice scattering is a function of ice particle concentration, size, shape, orientation, and density. Rangno and Hobbs (2005) found very high ice particle concentrations $\left(>500 \mathrm{~L}^{-1}\right)$ between $-3^{\circ}$ and $-10^{\circ} \mathrm{C}$ within small cumulonimbus in the vicinity of Kwajalein. They attributed the high ice concentrations to shattering of freezing drops and ice splinter production during riming. Further analysis of the size, shape, and density distribution of the ice particles and their associated radiative signatures is needed to unravel this apparent discrepancy between oceanic and continental ice scattering signatures. 


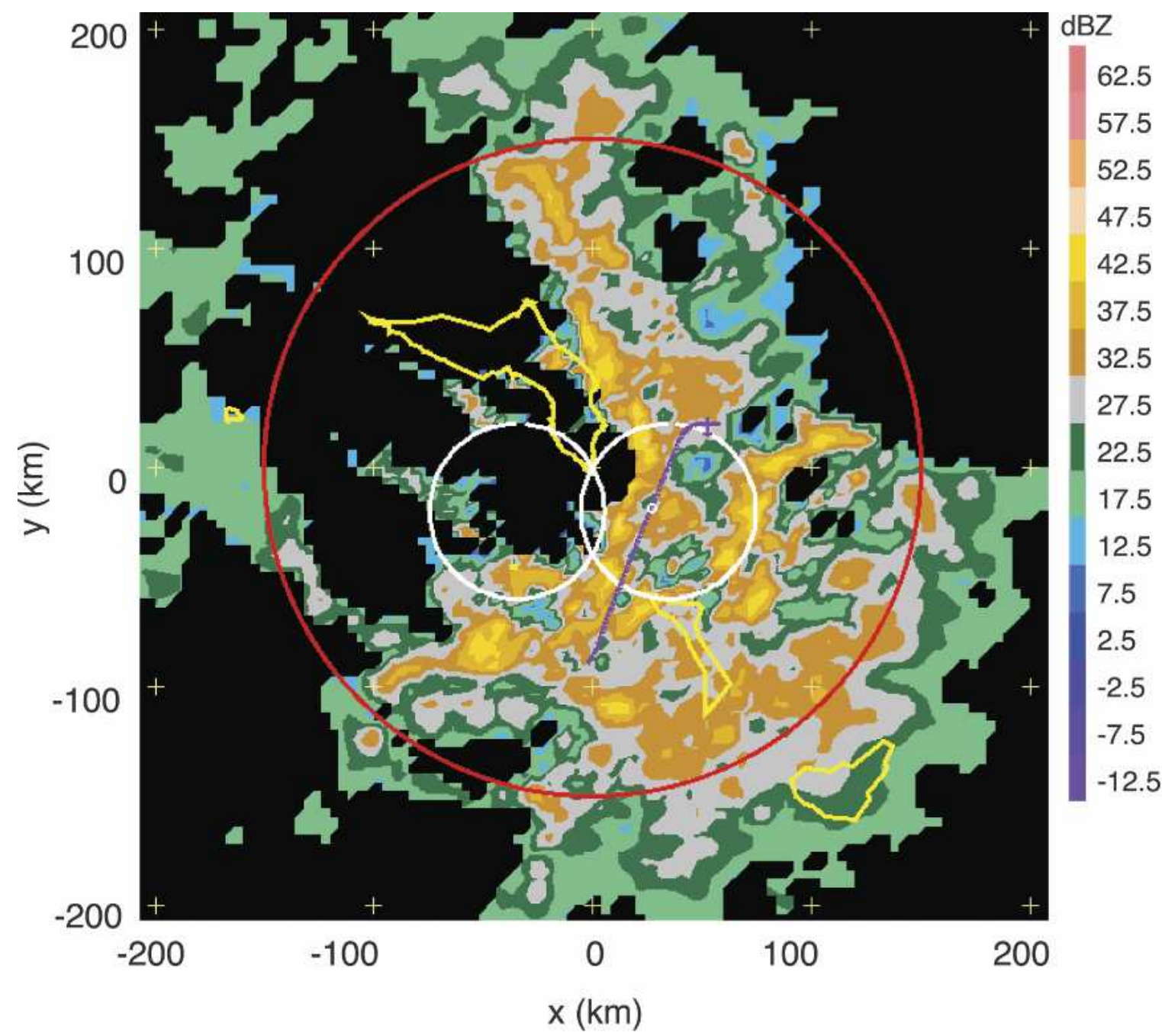

FIG. 19. Regional view of the 11 Aug 1999 storm at 2214 UTC obtained by Kwajalein S-band radar surveillance scan (appendix A). Radar reflectivities are interpolated to $4 \mathrm{~km} \times 4 \mathrm{~km}$. Red circle at $150-\mathrm{km}$ radius is the outer boundary of the region where three-dimensional volumetric radar data were obtained. White circles indicate boundaries of dual-Doppler lobes as in Fig. 6. Purple line shows the flight track of NASA DC-8.

\section{b. Precipitation particle images obtained by aircraft}

In situ particle imaging by airborne sensors provides information on the detailed nature and distribution of the hydrometeors within the precipitating cloud. Figure 21 shows DC-8 and Convair microphysical data obtained during portions of the flight legs shown in Fig. $20 \mathrm{a}$. The DC-8 data represent the particles at $12-\mathrm{km}$ altitude $\left(-47^{\circ} \mathrm{C}\right)$ near radar echo top, whereas the Convair data represent particles at $2.8-\mathrm{km}$ altitude $\left(12^{\circ} \mathrm{C}\right)$ within the rain layer. The sampling volumes of the in situ probes versus the ground-based radar differ by more than $10^{9}$, and the aircraft actively avoided heavy precipitation for safety reasons. Despite the sampling differences between the in situ and remotely sensed measurements, comparison of the in situ and remote observations can indicate the categories of hydromete- ors associated with particular remote sensing signatures and aid in physical interpretation of precipitating cloud development.

The concentration of ice particles at the altitude of the DC-8 was greater than the concentration of raindrops sampled by the Convair flying at lower altitude (Fig. 21b). This difference is consistent with aggregation of ice before the particles fall below the $0^{\circ} \mathrm{C}$ level. At the DC-8 altitude, total concentration was generally correlated with the reflectivity pattern below the aircraft (Fig. 21a); the lowest concentrations occurred at $32-37 \mathrm{~km}$ along the flight track between regions of higher reflectivity. In contrast, the total concentration of raindrops indicated by the Convair flying at lower levels (Fig. 21b) appears to have been unrelated to the reflectivity field.

The particle images recorded aboard the DC- 8 have 

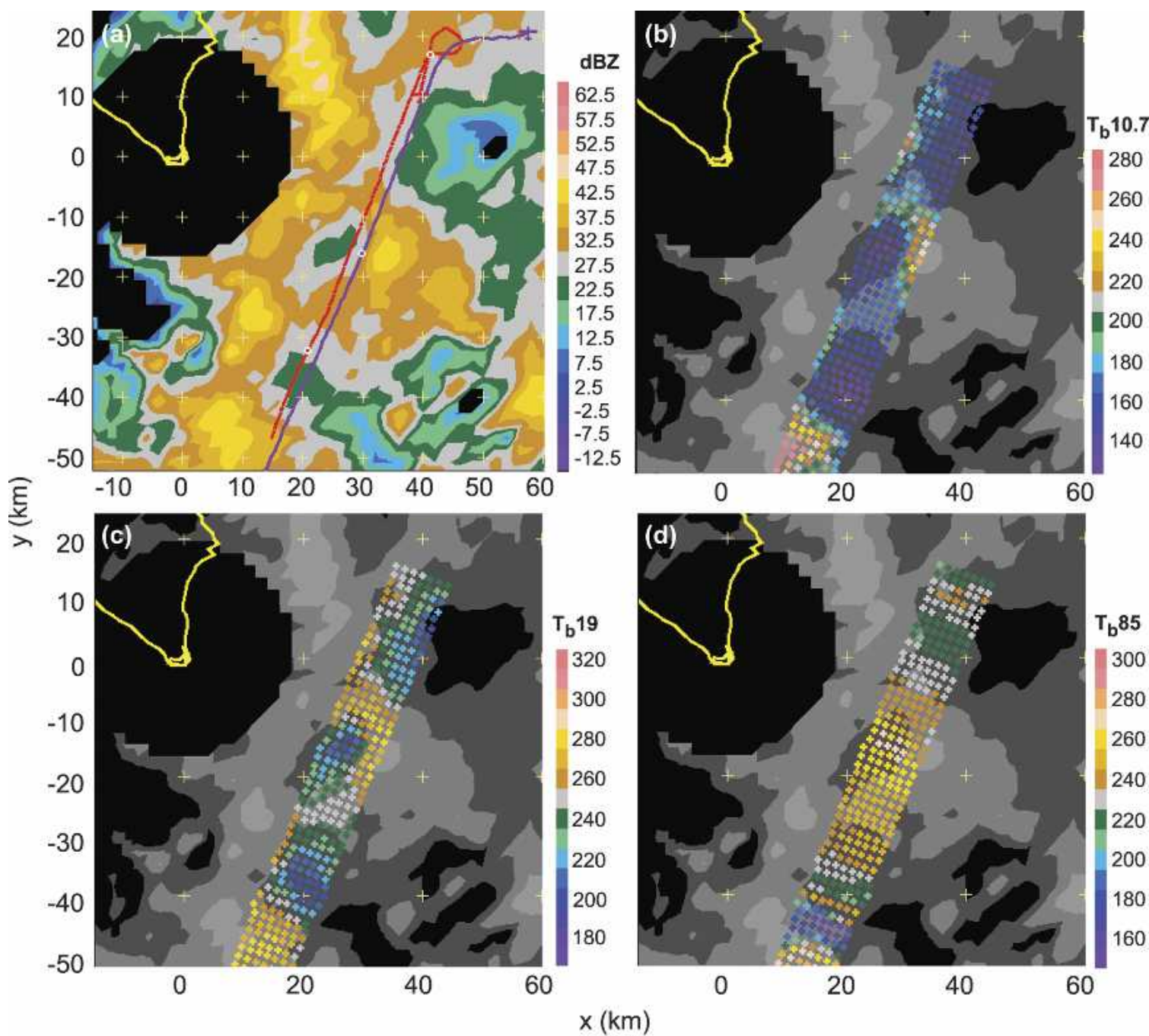

FIG. 20. Radar and passive microwave context for microphysics data shown in Fig. 21. (a) The $2 \mathrm{~km} \times 2 \mathrm{~km} \times 1.5 \mathrm{~km}$ interpolated reflectivity field at $1.5-\mathrm{km}$ altitude from the Kwajalein S-band radar. Purple line is the NASA DC-8 flight track; red line is UW Convair-580 flight track. Along the DC-8 track, AMPR data (colored dots) are laid over a simplified radar reflectivity field (gray shades for 20-30, 30-40, and 40-50 dBZ) for passive microwave frequencies of (b) 10.7, (c) 19, and (d) 85 GHz. (Processed AMPR data are provided through the courtesy of F. La Fontaine of MSFC and Y. Song of GSFC.)

been classified according to ice particle type and associated density (Kingsmill et al. 2004) in Fig. 21c. About $82 \%$ of the particles were too small to determine an image-type classification. These indeterminate particles have associated images containing fewer than 25 pixels, the minimum deemed necessary to determine particle shape (Kingsmill et al. 2004). In the two-dimensional cloud (2DC) probe size range $(0.15-1 \mathrm{~mm})$ shown in Fig. 21, the unclassified particles are likely high-density ice. Of the classifiable particles, low-density ice particles $(12 \%$ of total) are most common, followed by roughly equal amounts of high- and medium-density ice (each 3\% of total). The highest concentration of lowdensity ice particles appears above the more convective reflectivity pattern at $38-50 \mathrm{~km}$ along track rather than above the stratiform echo pattern between 14 and 32 $\mathrm{km}$ along track. A possible explanation is that the stronger updrafts in the convective region were actively advecting these and the other ice particle types to the $12-\mathrm{km}$ altitude of the DC-8. The stratiform region, with its generally lower vertical air velocity, is typically a region of previously active convection in which the vertical drafts have weakened and ice particles are generally settling downward (Houze 1997). After some time, the stratiform region will have lost many of its ice particles aloft as part of their general sedimentation down toward the $0^{\circ} \mathrm{C}$ level. Although not available for this particular flight leg, Citation in situ data obtained in other cases at altitudes between those of the DC- 8 and Convair may help to clarify the details of the vertical distribution of ice at intermediate levels as compared with the reflectivity pattern below in future studies. 

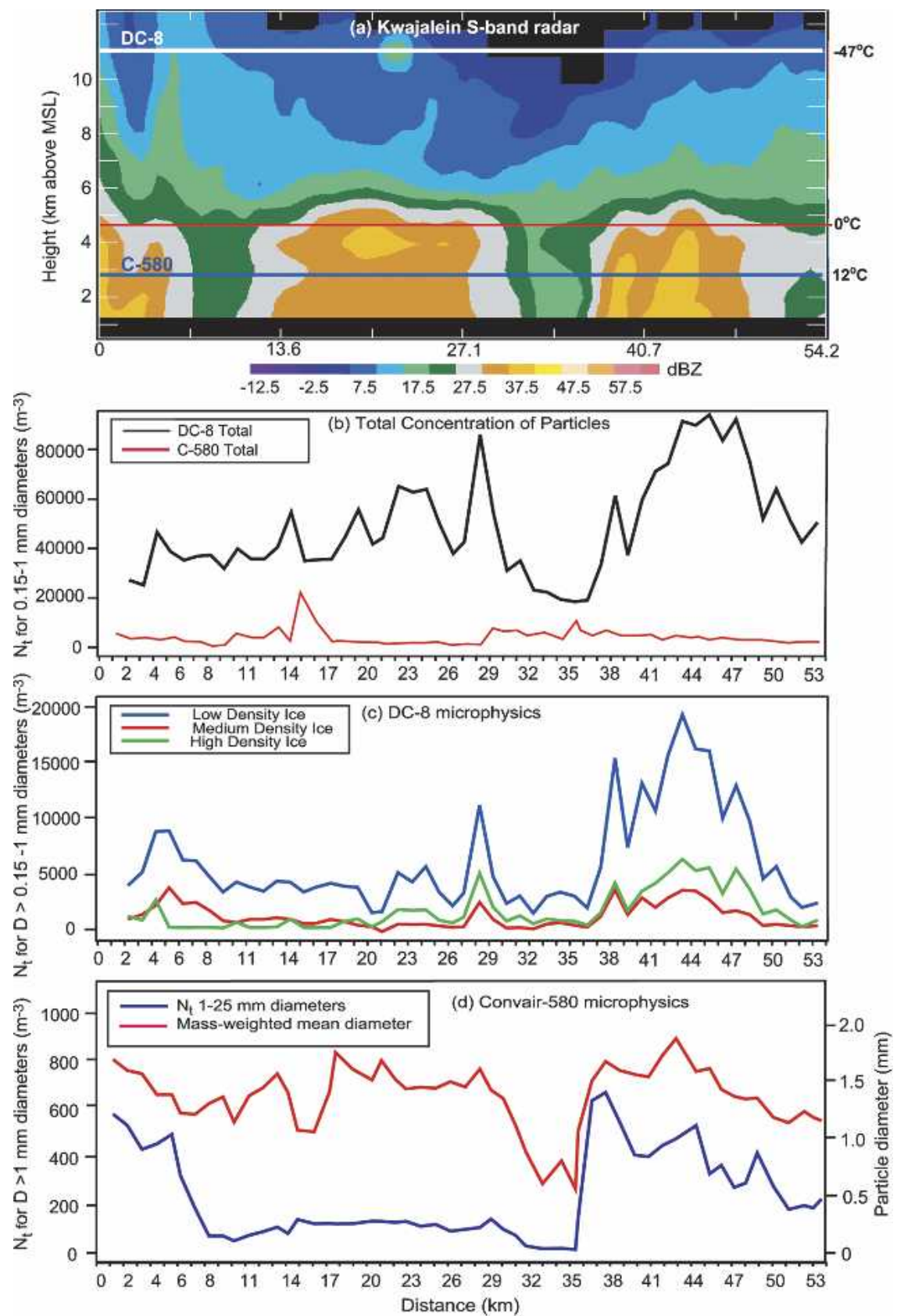

FIG. 21. (a) Vertical cross section of Kwajalein S-band radar data between straight portions of flight tracks of the NASA DC-8 and UW Convair-580 shown in Fig. 20a. Altitudes of aircraft and height of the $0^{\circ} \mathrm{C}$ level are indicated. Middle and lower panels show in situ microphysics data collected by each aircraft. (b) Total concentration of particles with $D>0.15$ $\mathrm{mm}$ for DC-8 and Convair-580. (c) Concentration of subsets of DC-8 particles categorized using ice-habit classification of TRMM Common Microphysics Products (Kingsmill et al. 2004). (d) Concentration of subset of Convair-580 rain particles with $D>1 \mathrm{~mm}$ and massweighted mean diameter for particles with $D>0.15 \mathrm{~mm}$. The DC-8 data are for 2208-2212 UTC, and the Convair-580 data are for 2158-2208 UTC 11 Aug 1999. (CMP version-4A data were processed by D. Kingsmill of University of Colorado/CIRES and P. Hobbs of UW and were obtained from the Goddard DAAC.) 
The Convair sampled only rain during this leg. Comparison of the curves for the total and the subset with diameter $>1 \mathrm{~mm}$ concentration (Figs. 21b,d) shows that roughly $90 \%$ of raindrops are less than $1 \mathrm{~mm}$ in diameter. Mass-weighted mean diameter varies from about 1.6-mm diameter in regions with reflectivity of $>30$ $\mathrm{dB} Z$ to $\sim 0.7-\mathrm{mm}$ diameter in weaker reflectivities. Near the edges of stronger echo (6-8 and 35-37 km along the flight track) there are sharp discontinuities in the concentration of raindrops of $>1$-mm diameter and the raindrop mean diameter (Fig. 21d). These discontinuities may represent relatively sharp boundaries in the microphysical processes such as drop coalescence.

\section{c. Statistical analysis of three-dimensional radar data}

The frequency distributions of reflectivity and horizontal divergence within convective and stratiform precipitation regions vary with height. Analysis of this height variation of radar observation statistics [as represented in a contoured-frequency-by-altitude diagram (CFAD)] provides insight into the microphysical processes and structure of precipitating cloud systems (Yuter and Houze 1995). Understanding the statistical differences between convective and stratiform precipitation regions aids in evaluating the TRMM latent heating product (Yang and Smith 2000; Tao et al. 2001). CFADs of echo over the total area and time period of the precipitation event (Yuter and Houze 1995) and mean vertical profiles of these quantities obtained for the region of the dual-Doppler lobes (Spooner 2001) are shown in Figs. 22 and 23. The convective/stratiform classification was made using a version of the texturebased algorithm developed by Churchill and Houze (1984), Steiner et al. (1995), and Yuter and Houze (1997). In this implementation of the classification, the algorithm is tuned for data interpolated to $1 \mathrm{~km}$ in the horizontal plane and vertical direction (appendix B). The convective and stratiform regions identified by the algorithm exclude regions with near-surface reflectivity $<15 \mathrm{dBZ}$. Echoes with reflectivities $<15 \mathrm{~dB} Z$ are grouped into a separate category called "weak echo" because they are below the TRMM PR detection threshold (Kummerow et al. 1998). The profile of average reflectivity above the weak surface echoes exhibits a local maximum near the melting level (Fig. 23a), indicating that the weak echo regions are predominately weakening stratiform precipitation rather than the initial stages of convective cells.
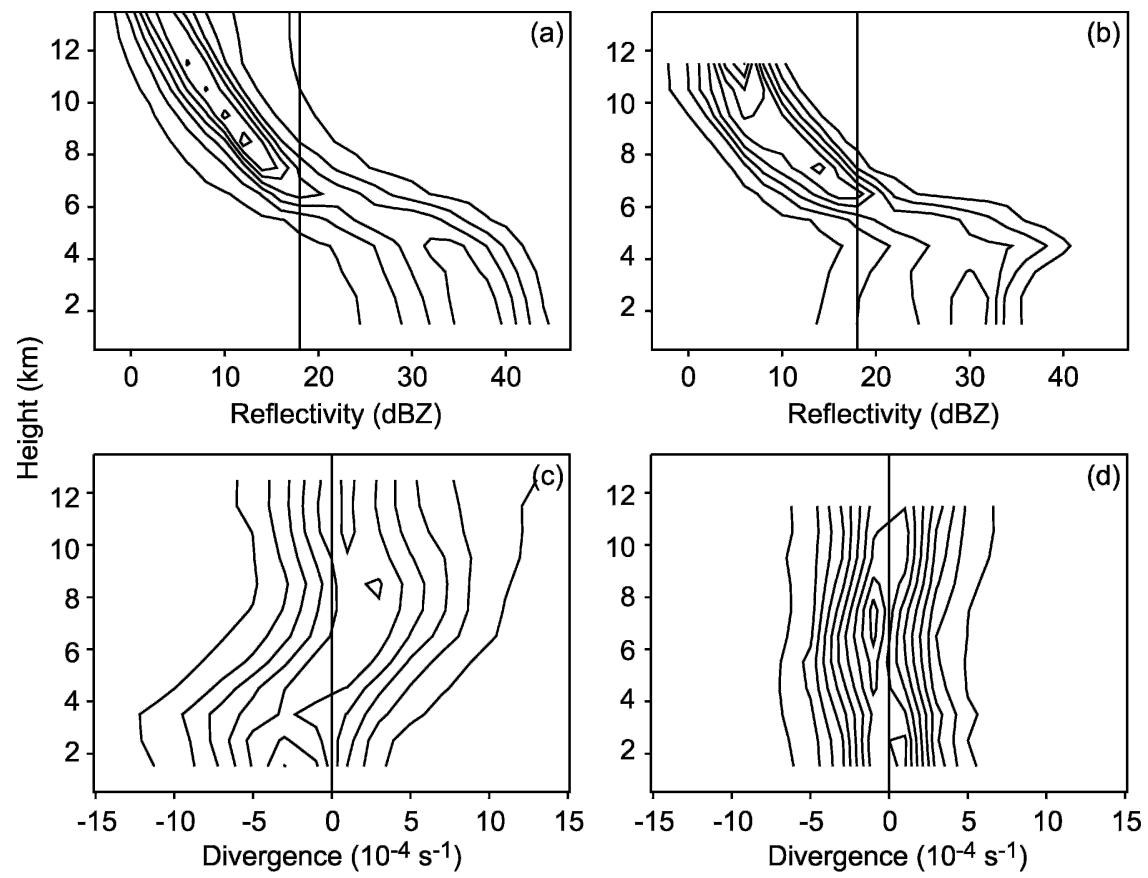

FIG. 22. Storm-total CFADs accumulated from 2023 UTC 11 Aug to 0400 UTC 12 Aug 1999 for the region within the dual-Doppler lobes. Statistics are derived from 38 merged radar volumes interpolated to $1 \mathrm{~km}$ in the horizontal plane and vertical direction. Each merged volume combines pairs of consecutive 6-min volume scans obtained at interleaved elevation angles. Reflectivity data were derived from S-band radar reflectivity only. Horizontal divergence was derived from dual-Doppler synthesis of S-band and Brown radial velocity data. (a) Convective-region reflectivity, (b) stratiform-region reflectivity, (c) convective-region horizontal divergence, and (d) stratiform-region horizontal divergence. For reflectivity CFADs, the bin size is $2 \mathrm{~dB}$ and the contour interval is $2 \% \mathrm{dBZ}^{-1} \mathrm{~km}^{-1}$. For divergence CFADs, the bin size is $2 \times 10^{-5} \mathrm{~s}^{-1}$ and the contour interval is $2 \% \mathrm{~s} \mathrm{~km}^{-1}$. 

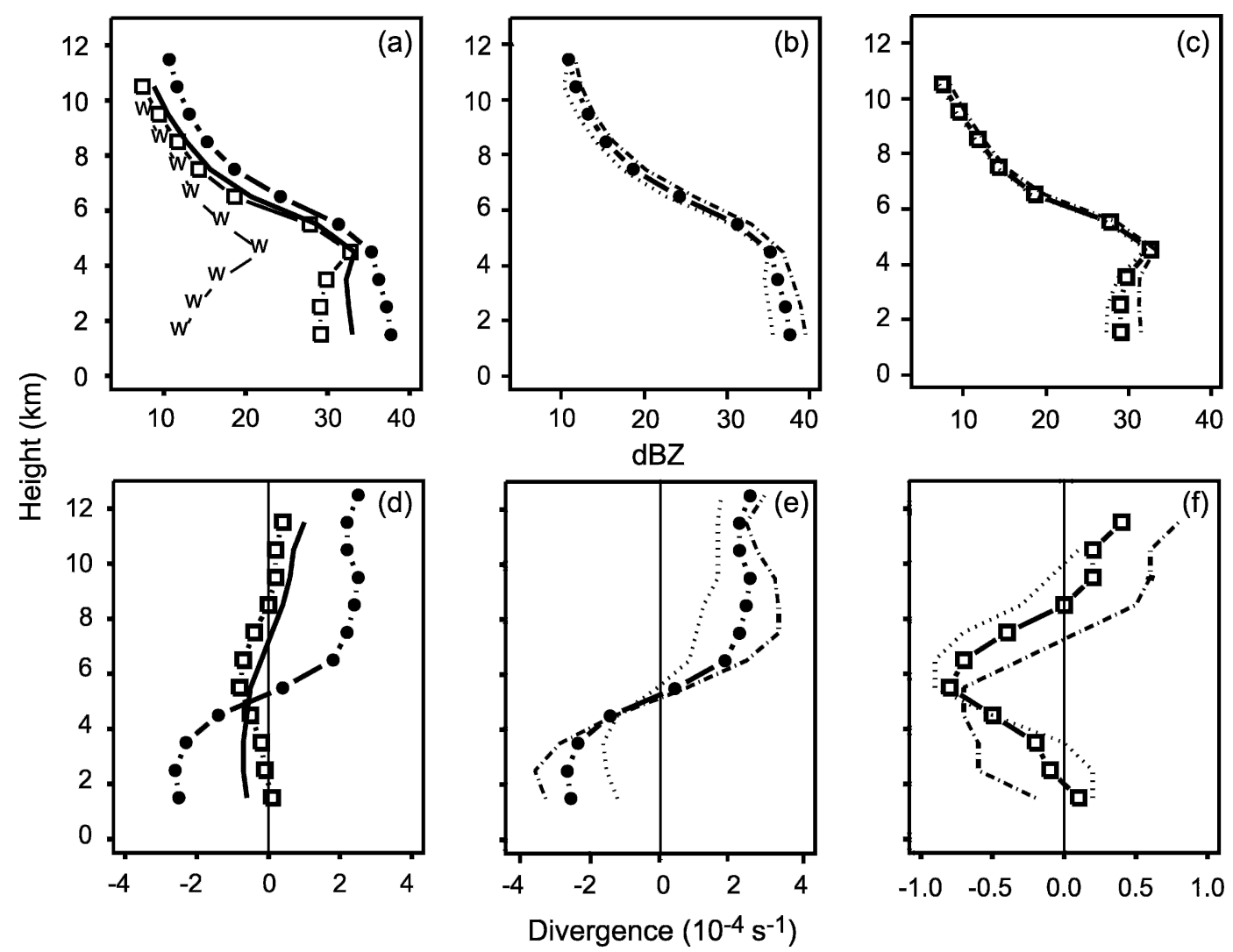

FIG. 23. Storm-total mean profiles with uncertainty for dataset described in Fig. 22. Uncertainty is associated with the varying size of the convection region as shown in Fig. 24. (a) Reflectivity profiles: total (solid line), convective, (circles), stratiform (squares), and weak echo with near-surface $Z<15 \mathrm{dBZ}$ ("w"). (b), (c) Convective and stratiform profiles, respectively, from (a) bracketed by profiles for larger convective regions (dotted) and for smaller convective regions (dashed). (d) Horizontal divergence profiles: total (solid line), convective (circles), and stratiform (squares). (e), (f) Convective and stratiform profiles from (d) bracketed by profiles for larger convective regions (dotted) and for smaller convective regions (dashed). Note that (f) shows a smaller range of divergence values (from $-1 \times 10^{-4}$ to $+1 \times 10^{-4} \mathrm{~s}^{-1}$ ) when compared with (d) and (e).

The overall patterns in the CFADs and profiles are similar to those for tropical oceanic precipitation obtained during TOGA COARE in the western Pacific warm pool (Mapes and Houze 1995). The reflectivity CFAD for the convective region shows higher modal values near the surface and a more rapid increase of reflectivity with decreasing height within ice above the melting level than does the stratiform-region CFAD. The stratiform-reflectivity CFAD shows the radar bright band at $\sim 4.5-\mathrm{km}$ altitude. The vertical slope of the mode at lower levels in the stratiform region indicates little to no precipitation growth, on average, below the melting level. In the convective CFAD, the mode within the rain layer shows increasing reflectivity with decreasing height at all levels, consistent with precipitation growth.

The divergence CFADs (Figs. 22c,d) have wider distributions in the convective regions than in the stratiform regions. The broader distribution of divergence implies a wider distribution of up- and downdraft velocities, as would be expected in the convective echo region (Houze 1997). The modal values of the divergence CFADs exhibit characteristic divergence profiles for convective and stratiform regions, with low-level convergence and upper-level divergence in convective regions and midlevel convergence sandwiched between lower- and upper-level divergence in stratiform regions (Houze 1982, 1989, 1997; Mapes and Houze 1995). The large area of stratiform precipitation within this case weights the total profile such that it closely resembles the stratiform profile (Fig. 23d).

\section{d. Doppler-radar-observed divergence profiles in relation to convective/stratiform classification}

The ability to estimate vertical profiles of heating from the TRMM PR data depends on the ability to subdivide the satellite-observed tropical rainfall accurately into convective and stratiform components (Tao et al. 2001; Schumacher et al. 2004). Because heating profiles are difficult to observe, the accuracy of heating profiles must be estimated indirectly. One indirect test is to determine whether the vertical profiles of diver- 
gence in convective and stratiform regions are distinct and consistent with the heating profiles associated with convective and stratiform precipitation areas. The divergence profile is proportional to the vertical profile of latent heating (Mapes and Houze 1995). Because the algorithm classifies precipitation areas as convective or stratiform on the basis of low-level reflectivity patterns, an independent measure of the column divergence in each type of region will test whether the precipitation pattern based convective/stratiform separation is physically consistent.

We perform a sensitivity test using the dual-Dopplerderived horizontal divergence profiles for the 11-12 August case. The sensitivity is estimated by varying the parameters of the convective/stratiform separation algorithm and computing the divergence profiles for each variation of the algorithm parameters (appendix B). The primary parameters of the algorithm are the assumed radius around the identified convective core that is classified as convective precipitation and the peakedness criterion for the identification of convective cores (e.g., Fig. 24). The peakedness criterion refers to the difference between echo intensity at the center of the convective core relative to the background reflectivity. Variations of these parameters yield "pure" subsetsthe convective subset for smaller convective regions and the stratiform subset for larger convective regions, which represent underestimates for the actual areas of these precipitation types and have less potential con- tamination from misclassification. Their "impure" counterparts are the convective subset of larger convective regions and the stratiform subset for smaller convective regions, which are likely to be contaminated by misclassified pixels.

A check on the reasonableness of the algorithm variations tests whether the associated mean profiles obtained from columns of radar echo classified as convective or stratiform encompass the true value. All of the variants of the stratiform reflectivity profile nearly coincide at altitudes above the radar bright band but differ slightly in magnitude in the rain region below (Fig. 23c). The impure variant of the convective profile, corresponding to the larger convective regions (Fig. 23b), shows some evidence of a bright band, similar to the total profile in Fig. 23a, indicating misclassification of some pixels of stratiform precipitation as convective and implying that the larger convective region variant is too large. The only divergence profile clearly deviating from the classic shape (Houze 1997, his Fig. 3) is the impure variant of the stratiform profile, corresponding to smaller convective regions and hence larger stratiform regions (Fig. 23f). When plotted on the same scale, this profile resembles the total profile in Fig. $23 \mathrm{~d}$, implying that the larger stratiform regions associated with the smaller convective region variant are too large. Because the reflectivity profile deviation from the classic profile occurred for the large convective region variant and the divergence profile deviation from the clas-

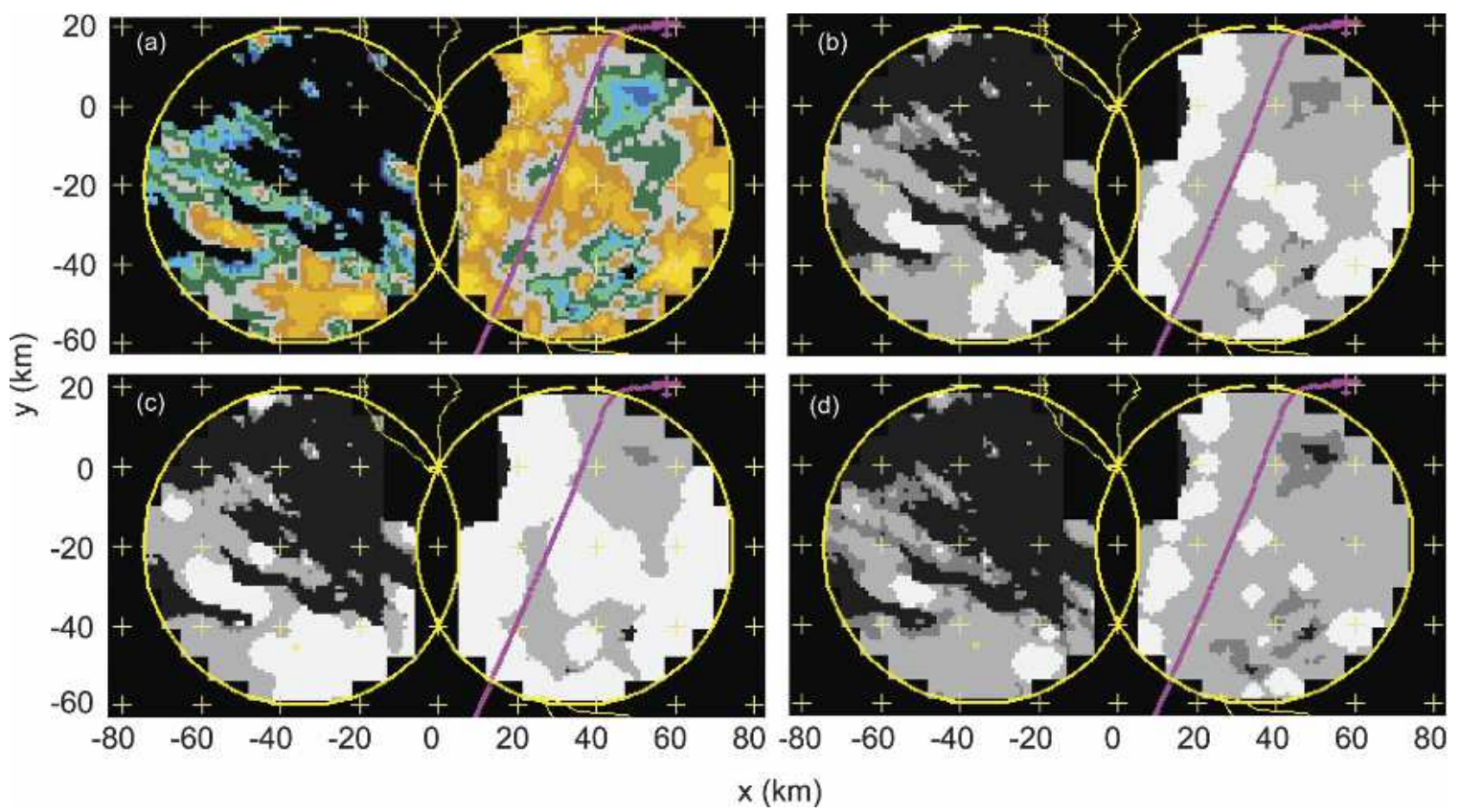

FIG. 24. Output from convective/stratiform classification algorithm variations used in Fig. 23, for example, data obtained within the dual-Doppler lobes at 2214 UTC 11 Aug 1999. The pink line in each panel indicates the flight track of the NASA DC-8. (a) The $1 \mathrm{~km}$ $\times 1 \mathrm{~km} \times 1 \mathrm{~km}$ interpolated reflectivity field for 1-km altitude used as input to the classification. Output of classification algorithm is shaded as follows: convective precipitation (white), stratiform precipitation (medium gray), weak echo (dark gray), and no echo or missing (black). Algorithm variations are (b) best-guess convective regions, stratiform includes $Z>15 \mathrm{~dB} Z$, (c) larger convective regions, stratiform includes $Z>10 \mathrm{~dB} Z$, and (d) smaller convective regions, stratiform includes $Z>20 \mathrm{~dB} Z$. 
sic profile occurred for the small convective region variant, it seems likely that these variations bracket the true value for convective region size and could potentially be used to constrain convective region size within the PR algorithm.

The sensitivity of the horizontal divergence profiles to the details of the convective/stratiform classification primarily involves magnitude and secondarily involves shape. The largest-magnitude variations are in the convective divergence profiles for which the ratio of reclassified pixels to total convective pixels is larger than for stratiform regions. The smallest and most intense convective regions are associated with the strongest nearsurface convergence. As the region classified as convective widens, the magnitude of low-level convergence decreases as older cells with downdrafts and low-level divergence are incorporated into the region classified as convective. Above the $0^{\circ} \mathrm{C}$ level, all of the convective profiles are divergent but the detailed shapes of the profiles differ, particularly in the heights of the local maxima, which correspond to changes in slope of the corresponding heating profile. Whether these changes in slope at small scales are significant to the larger-scale heating profile will require further analysis. The variations in the horizontal divergence profiles associated with uncertainties in convective/stratiform classification suggest that evaluation of the convective and stratiform latent heating product derived from the TRMM satellite is better served by a comparison of profile shape rather than absolute magnitude.

\section{Conclusions}

Preliminary results from KWAJEX indicate basic physical characteristics of the environment and precipitating cloud population over the open ocean surrounding Kwajalein Atoll, on the northern edge of the west Pacific ITCZ. Kwajalein's location at $8.7^{\circ} \mathrm{N}$, $167.7^{\circ} \mathrm{E}$ permits sampling of well-organized mesoscale convective systems associated with the ITCZ and less organized small-area precipitating convection that are frequently observed by the TRMM satellite. The KWAJEX datasets, in conjunction with the multiyear datasets from the TRMM Kwajalein GV site, are a unique source of information on open-ocean tropical precipitation. The examples and analyses presented in this paper illustrate the variety of and coordination among datasets obtained during the field project.

\section{a. Environmental context}

The Kwajalein region is characterized by persistent easterly winds from the surface to $300 \mathrm{hPa}$ and weak vertical wind shear (Figs. 7 and 9). The mean altitude of the $0^{\circ} \mathrm{C}$ level was $4787 \mathrm{~m}$, with a standard deviation of $144 \mathrm{~m}$ during the KWAJEX period. The mean atmosphere during KWAJEX exhibited potential instability for the layer from the surface to the $0^{\circ} \mathrm{C}$ level (Fig. 8).
KWAJEX occurred during a cold phase of ENSO (Fig. 13). The rainy-season months of July-December 1999 , within which KWAJEX was held, had less total rainfall and fewer large precipitating cloud systems than the same month period in 2000 and 2001 (Fig. 11).

\section{b. Rainfall characteristics}

During KWAJEX, the conditional mean rain rate for a $4-\mathrm{km}^{2}$ rainy pixel is $2.1 \mathrm{~mm} \mathrm{~h}^{-1}$, with a standard deviation of $0.96 \mathrm{~mm} \mathrm{~h}^{-1}$. The average hourly areal rain rate for the $150-\mathrm{km}$-radius domain surrounding Kwajalein, including regions where it is not raining, is $0.22 \mathrm{~mm}$ $\mathrm{h}^{-1}\left(5.3 \mathrm{~mm} \mathrm{day}^{-1}\right)$. The KWAJEX average areal rain rate is similar to the estimate for TOGA COARE of 5.4 $\mathrm{mm}$ day $^{-1}$, based on range-corrected shipboard radar data (Short et al. 1997). During the three largest organized precipitating events during KWAJEX (25-26 July, 11-12 August, and 2-3 September; Fig. 16), the $150-\mathrm{km}$-domain hourly areal average rain rates peaked at $1.4,2.7$, and $2.5 \mathrm{~mm} \mathrm{~h}^{-1}$, respectively (Fig. 17). Taking into account the limitations of the disdrometer sensitivity (Joss and Gori 1976) and instrument siting (section $3 \mathrm{~d})$, surface raindrop spectra $(D>0.3 \mathrm{~mm})$ appear to be approximately exponential (Fig. 10d).

For the 3-yr rainy-season radar dataset at Kwajalein, $50 \%$ of the sampled hours contain domain echo areas $<6400 \mathrm{~km}^{2}$, which account for $\sim 12 \%$ of the total rainfall. In the same sample, $50 \%$ of the rainy area is contributed by domain echo areas $>20000 \mathrm{~km}^{2}$, which occur in only $16 \%$ of the sampled hours.

\section{c. Lognormality of radar echo size distribution}

The horizontal dimensions of the rain areas follow a truncated lognormal distribution (Fig. 14), as has been observed previously over tropical oceans. Radar echoes over the Caribbean and the eastern tropical Atlantic Ocean also exhibit truncated lognormality (López 1977; Houze and Cheng 1977), as do cold cloud-top areas in satellite data over the oceans of the Indonesian archipelago (Williams and Houze 1987) and the west Pacific warm pool (Mapes and Houze 1992). This behavior appears to be rather general, and the population of precipitating clouds in a given tropical oceanic area probably can be described by the parameters of a truncated lognormal distribution.

\section{d. Diurnal behavior}

The diurnal variation of the precipitating cloud population in the Kwajalein region observed by radar (Fig. $15)$ is a strong function of cloud element size and resembles that seen in infrared satellite imagery over the near-equatorial western Pacific (TOGA COARE) in broad terms but differs in some details. The extrema of the large systems near Kwajalein peaked just before dawn and lagged the TOGA COARE large systems by about an hour. As in TOGA COARE, at Kwajalein the 
smallest radar echoes have a maximum in the afternoon, evidently related to the solar heating cycle. Unlike the TOGA COARE population, the small precipitation echoes do not exhibit a second maximum between midnight and dawn. The differences from TOGA COARE are probably traceable to the generally less frequent occurrence of large systems on the fringe of the ITCZ (Kwajalein) as opposed to the heart of the near-equatorial oceanic convective maximum (TOGA COARE).

\section{e. Vertical profile of hydrometeors}

The 39 aircraft flights in KWAJEX covered a broad sample of large and small precipitating cloud elements representative of the Kwajalein cloud population (Figs. 16 and 17). The airborne data were examined as a further characterization of the physics of the convective and stratiform components of the precipitating cloud population in KWAJEX.

Airborne downward-looking microwave radiometer data obtained by the DC- 8 aircraft flying across the region observed by the ground-based S-band radar indicated a separation between upper-level microphysical processes and low-altitude precipitation processes (Fig. 20). The lower-frequency emission channels (10.7 and $19 \mathrm{GHz}$ ), which are sensitive primarily to the rain layer below the $0^{\circ} \mathrm{C}$ level, showed horizontal patterns consistent with the low-level radar echo. The $85-\mathrm{GHz}$ channel, sensitive to scattering by ice particles aloft, showed poor spatial correlation between regions of maximum ice particle scattering and regions of high radar reflectivity at low levels.

The three KWAJEX aircraft also directly sampled the precipitation particles. In the example flight leg within a large cloud system (mesoscale convective system with a sizable stratiform region) examined in this study (Fig. 21), the concentration of rain drops sampled by the Convair 580 aircraft flying at lower levels $\left(12^{\circ} \mathrm{C}\right)$ averaged $\sim 10 \%$ of the concentration of ice particles sampled by the DC- 8 at upper levels $\left(-47^{\circ} \mathrm{C}\right)$.

The in situ particle samples obtained by the DC-8 aircraft at high levels showed the lowest concentrations of ice particles in the zones between heavy rain areas. The ice particles observed by the upper-level aircraft were mostly too small to identify in terms of their shapes. The concentrations of larger-size, classifiable ice particle types were distinctly greater in the convective regions than in the stratiform regions, possibly because the stratiform regions were zones of older convection where the larger ice particles transported upward in convective drafts had largely been removed from upper levels by sedimentation.

\section{f. Convective/stratiform separation, divergence, and implied heating profiles}

Because the convection in the Kwajalein region occurs on the fringes of the ITCZ, the fraction of the total rain falling from stratiform regions (usually associated with mesoscale convective systems) is somewhat less than in other parts of the Tropics, whereas the fraction of rain from shallow, isolated precipitating convective clouds is somewhat greater (Schumacher and Houze 2003a, b). The sample of convection observed in KWAJEX correspondingly exhibited a moderate amount of stratiform precipitation associated with mesoscale convective systems such as the 11-12 August system highlighted in this paper. CFADs of the radar reflectivity in KWAJEX were qualitatively similar to those obtained over the western Pacific warm pool in TOGA COARE (Mapes and Houze 1995).

Dividing tropical oceanic precipitation into convective and stratiform components is important in assessments of vertical profiles of heating in the Tropics (Tao et al. 2001; Schumacher et al. 2004). KWAJEX aimed to determine how accurately the radar echoes of the precipitating cloud population could be separated into its convective and stratiform components. Because divergence is proportional to the vertical gradient of heating, the CFADs of divergence in regions of dualDoppler radar coverage (by the atoll-based and shipbased scanning radars) were computed for the convective and stratiform regions identified by applying an algorithm (appendix B) to the radar reflectivity data. CFADs of divergence in the convective regions showed the expected wider distributions associated with convective up- and downdrafts as compared with stratiform regions (Fig. 22). The modal values of the divergence CFADs exhibited characteristic divergence profiles for convective and stratiform regions, with low-level convergence and upper-level divergence in convective regions and midlevel convergence sandwiched between lower- and upper-level divergence in stratiform regions.

The sensitivity of the mean divergence profiles (and by implication the heating profiles) to the details of the convective/stratiform separation of the echo population was tested by varying the parameters of the convective/stratiform separation algorithm (section 6b, appendix B). These variations of the algorithm parameters bracket the true value for convective region size and could potentially be used to constrain convective region size within the TRMM PR algorithm and other applications. The horizontal divergence profiles in KWAJEX were sensitive to the details of the convective/stratiform classification primarily in magnitude and secondarily in shape (Fig. 23). Above the $0^{\circ} \mathrm{C}$ level, all the convective profiles were divergent but the detailed shapes of the profiles differed. Whether these changes in slope at small scales are significant to the larger-scale heating profile will require further analysis.

Acknowledgments. We thank the over 100 participants from 30 institutions who made KWAJEX possible. Two Web sites serve as focal points for KWAJEX information. The KWAJEX Operations Center Web site (online at www.atmos.washington.edu/kwajex/) 
TABlE A1. Characteristics of the Brown C-band radar and Kwajalein S-band radars during KWAJEX. A total of 35.8 days of Brown $\mathrm{C}$ band and 51.7 days of Kwajalein S band were collected during KWAJEX.

\begin{tabular}{lll}
\hline \hline & \multicolumn{1}{c}{ Brown $\mathrm{C}$ band } & \multicolumn{1}{c}{ Kwajalein S band } \\
\hline Model & REI-55 & Modified DWSR-93S \\
Wavelength & $5.36 \mathrm{~cm}$ & $10.71 \mathrm{~cm}$ \\
Peak transmit power & $250 \mathrm{~kW}$ & $250 \mathrm{~kW}$ horizontal, 250 kW vertical \\
Pulse duration $(\mu \mathrm{s})$ & $2,1.2,0.8,0.5$ & 0.8 \\
Minimum detectable signal & $-114 \mathrm{dBm}$ & $-108 \mathrm{~dB} m$ \\
Antenna gain & $\sim 44 \mathrm{~dB}$ & $\sim 45 \mathrm{~dB}$ \\
PRF & Variable 250-2100 Hz & Variable 393-960 Hz \\
Polarization & Horizontal & Horizontal and vertical \\
Beamwidth & $0.95^{\circ}$ & $1.12^{\circ}$ \\
Antenna and radome dimensions & $4.3-\mathrm{m}$ parabolic dish, $5.5-\mathrm{m}$ sphere & 8.23 -m parabolic dish, 11.5 -m sphere \\
Antenna height & $33 \mathrm{~mm}$ above water line & $24.8 \mathrm{~m}$ MSL \\
Max scan speed & $36^{\circ} \mathrm{s}^{-1}$ & $16^{\circ} \mathrm{s}^{-1}$ \\
Elev range & $-0.5^{\circ}$ to $85^{\circ}$ & $-0.4^{\circ}$ to $90.5^{\circ}$ \\
Stabilization & Kongsberg, Inc., Seapath 200 & Not applicable $^{\circ}$ \\
Usable radar variables & $Z_{H}, V r$, shortwave & $Z_{H}, V_{r}$, shortwave \\
Radar processor and software & Sigmet, Inc., RVP7, RCP02, and IRIS & Sigmet RVP7, RCP02, and IRIS \\
& software V7.05 & software V7.05 \\
\hline
\end{tabular}

contains day-by-day status information and perusal products such as cloud photos, radar and satellite images, and quick-look plots from several instruments. The NASA Goddard DAAC (information online at daac.gsfc.nasa.gov/CAMPAIGN_DOCS/TRMM_FE/ $\mathrm{kwajex} / \mathrm{kwajex} . \mathrm{shtml}$ ) serves as the official archive of the KWAJEX datasets. Both Web sites also contain links to instrument-specific sites that have detailed information on the KWAJEX datasets and instruments. Funding for KWAJEX was provided by NASA and the NOAA Office of Global Programs. The success of KWAJEX owes much to the logistical planning and coordination with the USAKA by C. Sweetland, and the support of many departments within USAKA, especially the Range Support Department and the Communications Department. Invaluable contributions to project planning and execution were provided by L. Rose, G. Trapp, J. M. Fair, and the staff of Aeromet, Inc. TRMM Program Manager Ramesh Kakar and TRMM Office Head Otto Thiele were instrumental in facility allocation. We gratefully acknowledge C. Bretherton, V. Chandrasekar, D. Kingsmill, A. Sobel, and C. Spooner for their contributions to this paper. Candace Gudmundson edited the manuscript, and Kay Dewar and Beth Tully drafted the figures. Marc Michelsen provided software development and support. Wes Adkins, Dan Podhola, Robert Schaaf, and Tim Whitcomb processed datasets for analysis. The authors were supported by NASA TRMM Grants NAG5-9750, NAG5-9668, NAG 5 9729, NAG 5 13779, and NAG59717.

\section{APPENDIX A}

\section{S-Band and C-Band Radar Scan Strategies and Calibration for KWAJEX}

A scan strategy consisting of two time-coordinated $360^{\circ} 5$-min volume scans and one $360^{\circ}$ surveillance scan repeating every 12 min was used by both the Kwajalein S-band radar and the Brown C-band radar (Table A1). The details of dual-Doppler volume scans were determined using the National Center for Atmospheric Research scan optimizer (Burghart et al. 1991). The different hardware characteristics of the two radars made the optimal scans for each radar slightly different in terms of tilt sequence, scan speed, and pulse repetition frequency (PRF; Tables A2 and A3). Rather than match spatial resolutions that would constrain the ship dataset to the lower resolution of the slower-scanning Kwajalein radar, the scans were calculated for several echo-top heights $(6,8,10$, and $13 \mathrm{~km})$ to obtain the best vertical resolution from each radar given other scan constraints. Following the method of the Swiss Meteorological Agency (Joss et al. 1998), volume scans with a common lowest elevation angle and interleaved upper-

TABLE A2. Radar scan strategy for Kwajalein S-band radar during KWAJEX. Tilts are for the most commonly utilized pair of volume scans designed to top echoes of $13-\mathrm{km}$ height at ranges $\geq 25 \mathrm{~km}$. Max range indicates maximum range recorded.

\begin{tabular}{|c|c|c|c|c|c|c|c|c|}
\hline Name & Variables & ${ }^{\circ} \mathrm{s}^{-1}$ & $\begin{array}{l}\text { No. } \\
\text { tilts }\end{array}$ & $\begin{array}{c}\text { No. } \\
\text { samples }\end{array}$ & $\begin{array}{l}\text { Pulse width } \\
\qquad(\mu \mathrm{s})\end{array}$ & $\begin{array}{l}\text { Max range } \\
(\mathrm{km})\end{array}$ & $\begin{array}{l}\text { PRF } \\
(\mathrm{Hz})\end{array}$ & $\begin{array}{l}\text { Nyquist velocity } \\
\qquad\left(\mathrm{m} \mathrm{s}^{-1}\right)\end{array}$ \\
\hline Surveillance & $Z$ & 8 & 1 & 50 & 0.8 & 240 & 396 & Not applicable \\
\hline 5-min volume $\mathrm{A} / \mathrm{B}$ & $Z, V_{r}$ & 15 & 12 & 64 & 0.8 & 156 & 960 & 25.7 \\
\hline Tilts for volume A & $0.4,2.3,4.2$ & $.1,8.0$, & 11.8 & , $16.6,19$. & $23.2,27.6$ & & & \\
\hline Tilts for volume B & $0.4,1.4,3.3$ & $.2,7.1$, & 10.9 & $15.2,18$ & $21.2,25.3$ & & & \\
\hline
\end{tabular}


TABle A3. As in Table A2, but for the Brown C-band radar.

\begin{tabular}{lccccccrr}
\hline \hline \multicolumn{1}{c}{ Name } & Variables & ${ }^{\circ} \mathrm{s}^{-1}$ & $\begin{array}{c}\text { No. } \\
\text { tilts }\end{array}$ & $\begin{array}{c}\text { No. } \\
\text { samples }\end{array}$ & $\begin{array}{c}\text { Pulse width } \\
(\mu \mathrm{s})\end{array}$ & $\begin{array}{c}\text { Max range } \\
(\mathrm{km})\end{array}$ & $\begin{array}{c}\text { PRF } \\
(\mathrm{Hz})\end{array}$ & $\begin{array}{c}\text { Nyquist velocity } \\
\left(\mathrm{m} \mathrm{s}^{-1}\right)\end{array}$ \\
\hline Surveillance & $Z$ & 5 & 2 & 50 & 2 & 240 & 250 & Not applicable \\
5-min volume A/B & $Z, V_{r}$ & 20 & 16 & 60 & 1.2 & 125 & 1200 & 16.1 \\
Tilts for volume A & $0.4,1.6,2.8,3.9,5.1,6.3,7.5,8.7,9.9,11.4,13.1,15.1,17.3,20.0,23.1,26.8$ & & \\
Tilts for volume B & $0.4,1.0,2.2,3.3,4.5,5.7,6.9,8.1,9.3,10.6,12.2,14.0,16.1,18.6,21.5,24.9$ & & \\
\hline
\end{tabular}

elevation angles were employed to give the users of the radar data the option of utilizing the data either at a higher time resolution with coarser vertical resolution or at a coarser time resolution with higher vertical resolution.

During and subsequent to the project, several independent estimates of the S-band radar reflectivity calibration offset were made utilizing engineering measurements of the radar hardware (G. Mueller 2000, personal communication), comparison with version-4 TRMM PR data (Bolen and Chandrasekar 2000), and comparison with rain gauge data (C. Schumacher 2000, personal communication). The consensus calibration correction with uncertainty from these estimates is $5 \mathrm{~dB}$ $\pm 2 \mathrm{~dB}$ (details may be found online at www.atmos. washington.edu/kwajex/ops-web/CSU/calibration. $\mathrm{html}$ ). When the PR comparison was rerun with TRMM version-5 data, the calibration offset changed by $+1 \mathrm{~dB}$ as compared with TRMM version- 4 PR data (V. Chandrasekar 2003, personal communication). A $+5-\mathrm{dB}$ calibration correction has been added to the processed S-band radar data used in this paper. Tethered and released sphere calibrations performed during the experiment were too noisy to obtain reliable estimates. Because the Brown C-band radar's primary role during KWAJEX was to provide radial velocity data for dual-Doppler analysis, effort has not been expended to calibrate its radar reflectivity data. After KWAJEX, the Kwajalein S-band radar data have continued to be calibrated by comparison with the TRMM PR (Houze et al. 2004).

\section{APPENDIX B}

\section{Convective/Stratiform Separation Algorithm and Its Variations Applied to 1-km-Resolution Data}

The objective classification of convection and stratiform precipitation (Houze 1997) using low-level radar reflectivity data was first defined by Churchill and Houze (1984), based on ideas presented in Houze (1973). The basic technique involves identification of

TABLE B1. Table of parameters among different implementations of convective/stratiform classification algorithm for and following Churchill and Houze (1984). Radius for computing $Z_{\mathrm{bg}}$ is $11 \mathrm{~km}$ for all implementations. In the $\Delta Z_{\mathrm{cc}}$ column, the division symbol stands for floating point division. In the convective radius column, the division symbol stands for integer division. Convective radii are defined to be integer values.

\begin{tabular}{|c|c|c|c|c|c|}
\hline Study & $\begin{array}{l}\text { Horizontal } \\
\text { resolution } \\
\left(\mathrm{km}^{2}\right)\end{array}$ & $\Delta Z_{\mathrm{cc}}(\mathrm{dB})$ & $\begin{array}{c}Z_{\mathrm{ti}} \\
(\mathrm{dBZ})\end{array}$ & Convective radius $R(\mathrm{~km})$ & $Z_{\mathrm{we}}(\mathrm{dBZ})$ \\
\hline $\begin{array}{l}\text { Churchill and Houze } \\
\text { (1984) }\end{array}$ & 16 & 4.5 & 40 & 6 for all $Z_{\mathrm{bg}}$ & Not applicable \\
\hline Steiner et al. (1995) & 4 & $\begin{array}{l}\text { for } 0 \leq Z_{\mathrm{bg}}<42.43 \text { : } \\
\quad \Delta Z_{\mathrm{cc}}=10-Z_{\mathrm{bg}}^{2} / 180 ; \\
\quad \text { for } Z_{\mathrm{bg}}<0: \Delta Z_{\mathrm{cc}}=10 \\
\quad \text { for } Z_{\mathrm{b} \sigma} \geq 42.43: \Delta Z_{\mathrm{cc}}=0\end{array}$ & 40 & $\begin{array}{l}\text { For } 25 \mathrm{~dB} Z \leq Z_{\mathrm{bg}}<40 \mathrm{~dB} Z: \\
\quad R=2+\left(Z_{\mathrm{bg}}-25\right) / 5 \\
\quad \text { for } Z_{\mathrm{bg}}<25 \mathrm{~dB} Z: R=1 \\
\quad \text { for } Z_{\mathrm{bo}} \geq 40 \mathrm{~dB} Z: R=5\end{array}$ & Not applicable \\
\hline $\begin{array}{l}\text { Yuter and Houze } \\
\text { (1997) }\end{array}$ & 4 & $\begin{array}{l}\Delta Z_{\mathrm{cc}}=a \cos \left[\left(\pi Z_{\mathrm{bg}}\right) /(2 b)\right] \\
\quad \text { where } a=8, b=64\end{array}$ & $46^{*}$ & As in Steiner et al. (1995) & 15 \\
\hline This study: best & 1 & $\begin{array}{l}\text { As in Yuter and Houze (1997), } \\
\text { but } b=55\end{array}$ & 40 & $\begin{array}{l}\text { For } 15 \mathrm{~dB} Z \leq Z_{\mathrm{bg}}<30 \mathrm{~dB} Z \text { : } \\
\quad R=2+\left(Z_{\mathrm{bg}}-15\right) / 5 \\
\text { for } Z_{\mathrm{bg}}<15 \mathrm{~dB} Z: R=1 \\
\quad \text { for } Z_{\mathrm{bg}} \geq 30 \mathrm{~dB} Z, R=5\end{array}$ & 15 \\
\hline $\begin{array}{l}\text { This study: smaller } \\
\text { convective regions }\end{array}$ & 1 & $\begin{array}{l}\text { As in best except applied to } \\
Z \text { values reduced by } 5 \mathrm{~dB}\end{array}$ & 45 & $\begin{array}{l}\text { For } 20 \mathrm{~dB} Z \leq Z_{\mathrm{bg}}<35 \mathrm{~dB} Z: \\
\quad R=2+\left(Z_{\mathrm{bg}}-20\right) / 5 \\
\quad \text { for } Z_{\mathrm{bg}}<20 \mathrm{~dB} Z: R=1 \\
\quad \text { for } Z_{\mathrm{bg}} \geq 35 \mathrm{~dB} Z, R=5\end{array}$ & 20 \\
\hline $\begin{array}{l}\text { This study: larger } \\
\text { convective regions }\end{array}$ & 1 & $\begin{array}{l}\text { As in best except applied to } \\
Z \text { values increased by } 5 \mathrm{~dB}\end{array}$ & 35 & $\begin{array}{l}\text { For } 10 \mathrm{~dB} Z \leq Z_{\mathrm{bg}}<25 \mathrm{~dB} Z \\
\quad R=2+\left(Z_{\mathrm{bg}}-10\right) / 5 \\
\quad \text { for } Z_{\mathrm{bg}}<10 \mathrm{~dB} Z: R=1 \\
\quad \text { for } Z_{\mathrm{bg}} \geq 25 \mathrm{~dB} Z, R=5\end{array}$ & 10 \\
\hline
\end{tabular}

* For Yuter and Houze (1997), $Z_{\mathrm{ti}}$ was only used when the aircraft was below 1-km altitude and the data were uncontaminated by the bright band. 
convective cores, pixels whose reflectivity exceeds by at least $\Delta Z_{\mathrm{cc}}$ the average reflectivity in the surrounding echo region, also called the background reflectivity $\left(Z_{\mathrm{bg}}\right)$. The computation of the $Z_{\mathrm{bg}}$ excludes nonraining pixels. Pixels with reflectivities above a threshold intensity $\left(Z_{\mathrm{ti}}\right)$ are also classified as convective cores. This latter criterion is needed because intense cells can sometimes be crowded together. The second part of the method classifies the region within the "convective radius" $R$ of the convective core as convective precipitation. The remaining precipitation echo is classified either as stratiform or is subdivided into stratiform and weak echo using a reflectivity threshold $\left(Z_{\text {we }}\right)$. Churchill and Houze (1984) employed the technique on radar reflectivity data at $4 \mathrm{~km} \times 4 \mathrm{~km}$ resolution obtained over the South China Sea during the Monsoon Experiment (MONEX). Steiner et al. (1995) were the first to apply the technique to radar reflectivity data at $2 \mathrm{~km} \times$ $2 \mathrm{~km}$ resolution. They recognized the spatial-scale dependence of the classification parameters and proposed refinements to the peakedness and convective radius parameters. Both the peakedness criterion and the convective radius were made functions of $Z_{\mathrm{bg}}$. The parameters presented in Steiner et al. (1995) were tuned for radar data obtained near Darwin, Australia, using the vertical structure of radar echoes in regions where it was possible to detect a bright band. Steiner et al. (1995) warned that application of the algorithm to radar datasets obtained in different precipitation regimes, and with different radar beamwidths, sensitivity, and scan strategies, required tuning of the peakedness and intensity criteria. They found that the convective radius was primarily a function of grid resolution rather than precipitation regime. Yuter and Houze (1997) applied the algorithm to aircraft radar data obtained over the TOGA COARE region. They generalized the peakedness criteria as a cosine function to make it easier to adjust. For the TOGA COARE dataset, the difficulty in removing $100 \%$ of the sea clutter echo necessitated distinguishing stratiform from the weak echo because the latter could include sea clutter. In the current study the algorithm is applied to Kwajalein S-band radar data interpolated to $1-\mathrm{km}$ horizontal resolution, requiring a retuning of the algorithm parameters using comparisons with the vertical precipitation structure for reasons of different interpolated resolution, radar, and precipitation regime as compared with previous implementations. Table B1 provides the specifications of the parameters used in this study in comparison with the previous implementations and the manner in which the parameters were varied to yield the smaller and larger convective regions (section $6 \mathrm{~d}$ ).

\section{REFERENCES}

Adkins, W., and S. E. Yuter, 2001: Report on potential tropical open ocean precipitation validation sites. NASA Global Precipitation Mission Reports NASA/TM 2002-210010, 77 pp. [Available online at gpmscience.gsfc.nasa.gov.]
Arakawa, A., and W. H. Schubert, 1974: Interaction of a cumulus ensemble with the large-scale environment: Part I. J. Atmos. Sci., 31, 674-701.

Awaka, J., T. Iguchi, and K. Okamoto, 1998: Early results on rain type classification by the Tropical Rainfall Measuring Mission (TRMM) precipitation radar. Proc. URSI-F Symp. on Wave Propagation and Remote Sensing, Aveiro, Portugal, Institute for the Protection and the Security of the Citizen, Directorate General Joint Research Centre of the European Commission, 143-146.

Battan, L. J., 1973: Radar Observation of the Atmosphere. University of Chicago Press, $324 \mathrm{pp}$.

Betts, A. K., J. D. Fuentes, M. Garstang, and J. H. Ball, 2002: Surface diurnal cycle and boundary-layer structure over Rondônia during the rainy season. J. Geophys. Res., 107, 8065, doi:1029/2001JD000356.

Bolen, S. M., and V. Chandrasekar, 2000: Quantitative cross validation of space-based and ground-based radar observations. J. Appl. Meteor., 39, 2071-2079.

Bolton, D., 1980: The computation of equivalent potential temperature. Mon. Wea. Rev., 108, 1046-1053.

Burghart, C., P. J. Wyngaard, P. H. Herzegh, and J. W. Wilson, 1991: A program for optimization of meteorological radar scanning. Preprints, 24th Conf. on Radar Meteorology, Tallahassee, FL, Amer. Meteor. Soc., 573-576.

Byers, H. R., 1948: The use of radar in determining the amount of rain falling over a small area. Eos, Trans. Amer. Geophys. Union, 29, 187-196.

Chen, S. S., and R. A. Houze Jr., 1997: Diurnal variation of deep convective systems over the tropical Pacific warm pool. Quart. J. Roy. Meteor. Soc., 123, 357-388.

$\_,-$, and B. E. Mapes, 1996: Multiscale variability of deep convection in relation to large-scale circulation in TOGA COARE. J. Atmos. Sci., 53, 1380-1409.

Churchill, D. D., and R. A. Houze Jr., 1984: Development and structure of winter monsoon cloud clusters on 10 December 1978. J. Atmos. Sci., 41, 933-960.

Contreras, R. F., W. J. Plant, W. C. Keller, K. Hayes, and J. Nystuen, 2003: Effects of rain on $\mathrm{K}_{\mathrm{u}}$ band backscatter from the ocean. J. Geophys. Res., 108, 3165, doi:10.1029/ 2001JC001255.

Dennis, A. S., and F. G. Fernald, 1963: Frequency distributions of shower sizes. J. Appl. Meteor., 2, 767-769.

Durden, S. L., E. Im, F. K. Li, W. Ricketts, A. Tanner, and W. Wilson, 1994: ARMAR: An airborne rain-mapping radar. J. Atmos. Oceanic Technol., 11, 727-737.

,-- Z. S. Haddad, and L. Li, 2003: Comparison of TRMM precipitation radar and airborne radar data. J. Appl. Meteor., 42, 769-774.

Elliot, W. P., R. J. Moss, and W. H. Blackmore, 2002: Recent changes in NWS upper-air observations with emphasis on changes from VIZ to Vaisala radiosondes. Bull. Amer. Meteor. Soc., 83, 1003-1017.

Gage, K. S., C. R. Williams, W. L. Clark, P. E. Johnson, and D. A. Carter, 2002: Profiler contributions to Tropical Rainfall Measuring Mission (TRMM) ground validation field campaigns. J. Atmos. Oceanic Technol., 19, 843-863.

Heymsfield, A. J., A. Bansemer, P. R. Field, S. L. Durden, J. L. Stith, J. E. Dye, W. Hall, and C. A. Grainger, 2002: Observations and parameterizations of particle size distributions in deep tropical cirrus and stratiform precipitating clouds: Results from in situ observations in TRMM field campaigns. $J$. Atmos. Sci., 59, 3457-3491.

Heymsfield, G. M., and R. Fulton, 1988: Comparison of highaltitude remote aircraft measurements with radar structure of an Oklahoma thunderstorm: Implications for precipitation estimation from space. Mon. Wea. Rev., 116, 1157-1174.

Hitschfeld, W., and J. Bordan, 1954: Errors inherent in radar measurements of rainfall at attenuating wavelengths. J. Meteor., 11, 58-67. 
Hobbs, P. V., 1974: Ice Physics. Oxford Press, 837 pp.

—, 2000: Summary of University of Washington Convair-580 research flights for KWAJEX/TRMM in the Marshall Islands (25 July-15 September 1999). University of Washington KWAJEX/TRMM Field Project Tech. Rep., 84 pp.

Houze, R. A., Jr., 1973: A climatological study of vertical transports by cumulus-scale convection. J. Atmos. Sci., 30, 11121123.

-, 1977: Structure and dynamics of a tropical squall-line system. Mon. Wea. Rev., 105, 1540-1567.

- 1982: Cloud clusters and large-scale vertical motions in the Tropics. J. Meteor. Soc. Japan, 60, 396-410.

_ 1989: Observed structure of mesoscale convective systems and implications for large-scale heating. Quart. J. Roy. Meteor. Soc., 115, 425-461.

— 1997: Stratiform precipitation in regions of convection: A meteorological paradox? Bull. Amer. Meteor. Soc., 78, 2179 2196.

— , and C.-P. Cheng, 1977: Radar characteristics of tropical convection observed during GATE: Mean properties and trends over the summer season. Mon. Wea. Rev., 105, 964-980.

- , and A. K. Betts, 1981: Convection in GATE. Rev. Geophys. Space Phys., 19, 541-576.

- S. Brodzik, C. Schumacher, S. E. Yuter, and C. R. Williams, 2004: Uncertainties in oceanic radar rain maps at Kwajalein and implications for satellite validation. J. Appl. Meteor., 43, 1114-1132.

Iguchi, T., T. Kozu, R. Meneghini, J. Awaka, and K. Okamoto, 2000: Rain-profiling algorithm for TRMM precipitation radar. J. Appl. Meteor., 39, 2038-2052.

Joss, J., and E. G. Gori, 1976: The parameterization of raindrop size distributions. Riv. Ital. Geofis, 3, 275-283.

—_, and Coauthors, 1998: Operational Use of Radar for Precipitation Measurements in Switzerland. vdf Hochschulverlag AG an der ETH Zürich, 108 pp.

Kaneyasu, N., P. V. Hobbs, Y. Ishizaka, and G.-W. Qian, 2001: Aerosol properties around marine tropical cumulus. J. Geophys. Res., 106, 14 435-14 445.

Kim, M.-J., J. A. Weinman, and R. A. Houze Jr., 2004: Validation of maritime rainfall retrievals from TRMM microwave radiometer. J. Appl. Meteor., 43, 847-859.

Kingsmill, D. E., and Coauthors, 2004: TRMM common microphysics products: A tool for evaluating spaceborne precipitation retrieval algorithms. J. Appl. Meteor., 43, 1598-1618.

Kummerow, C., and L. Giglio, 1994: A passive microwave technique for estimating rainfall and vertical structure information from space. Part I: Algorithm description. J. Appl. Meteor., 33, 3-18.

—_ W. Barnes, T. Kozu, J. Shue, and J. Simpson, 1998: The Tropical Rainfall Measuring Mission (TRMM) sensor package. J. Atmos. Oceanic Technol., 15, 809-817.

— , and Coauthors, 2000: The status of the Tropical Rainfall Measuring Mission (TRMM) after two years in orbit. J. Appl. Meteor., 39, 1965-1982.

Lawrence, J. R., and S. D. Gedzelman, 2003: Tropical ice core isotopes: Do they reflect changes in storm activity? Geophys. Res. Lett., 30, 1072, doi:10.1029/2002GL015906.

Lin, X., and R. H. Johnson, 1996: Heating, moistening, and rainfall over the western Pacific warm pool during TOGA COARE. J. Atmos. Sci., 53, 3367-3383.

Loehrer, S. M., T. A. Edmands, and J. A. Moore, 1996: TOGA COARE upper-air sounding data archive: Development and quality control procedures. Bull. Amer. Meteor. Soc., 77, 2651-2671.

López, R. E., 1977: The lognormal distribution and cumulus cloud populations. Mon. Wea. Rev., 105, 865-872.

Lucas, C., E. J. Zipser, and M. A. LeMone, 1994: Vertical velocity in oceanic convection off tropical Australia. J. Atmos. Sci., 51, 3183-3193.
, and B. S. Ferrier, 2000: Sensitivity of tropical west Pacific oceanic squall lines to tropospheric wind and moisture profiles. J. Atmos. Sci., 57, 2351-2373.

Mapes, B. E., 1993: Gregarious tropical convection. J. Atmos. Sci., 50, 2026-2037.

, and R. A. Houze Jr., 1992: Satellite-observed cloud clusters in the TOGA COARE domain. TOGA Notes, April, 5-7.

- and - 1995: Diabatic divergence profiles in western $\mathrm{Pa}$ cific mesoscale convective systems. J. Atmos. Sci., 52, 18071828.

- P. E. Ciesielski, and R. H. Johnson, 2003: Sampling errors in rawinsonde-array budgets. J. Atmos. Sci., 60, 2697-2714.

Marks, D. A., and Coauthors, 2000: Climatological processing and product development for the TRMM Ground Validation Program. Phys. Chem. Earth, 25B, 871-876.

Meneghini, R., and T. Kozu, 1990: Spaceborne Weather Radar. Artech House, 197 pp.

—, T. Iguchi, T. Kozu, L. Liao, K. Okamoto, J. A. Jones, and J. Kwiatkowski, 2000: Use of surface reference technique for path attenuation estimates from the TRMM precipitation radar. J. Appl. Meteor., 39, 2053-2070.

Mugnai, A., and E. A. Smith, 1988: Radiative transfer to space through a precipitating cloud at multiple microwave frequencies. Part I: Model description. J. Appl. Meteor., 27, 10551073.

_, _ and G. J. Tripoli, 1993: Foundations for statisticalphysical precipitation retrieval from passive microwave satellite measurements. Part II: Emission source and generalized weighting function properties of a time-dependent cloud-radiation model. J. Appl. Meteor., 32, 17-39.

Nesbitt, S. W., and E. J. Zipser, 2003: The diurnal cycle of rainfall and convective intensity according to three years of TRMM measurements. J. Climate, 16, 1456-1475.

Ooyama, K., 1971: A theory on parameterization of cumulus convection. J. Meteor. Soc. Japan, 49, 744-756.

Rangno, A. L., and P. V. Hobbs, 2004: Microstructures and precipitation development in cumulus and small cumulonimbus clouds over the warm pool of the tropical Pacific Ocean. Quart. J. Roy. Meteor., 131, 639-674.

Reed, R. J., and E. E. Recker, 1971: Structure and properties of synoptic-scale wave disturbances in the equatorial western Pacific. J. Atmos. Sci., 28, 1117-1133.

Riehl, H., and J. S. Malkus, 1958: On the heat balance in the equatorial trough zone. Geophysica, 6, 503-538.

Schumacher, C., and R. A. Houze Jr., 2000: Comparison of radar data from the TRMM satellite and Kwajalein oceanic validation site. J. Appl. Meteor., 39, 2151-2164.

, and _ 2003a: Stratiform rain in the Tropics as seen by the TRMM precipitation radar. J. Climate, 16, 1739-1756.

, and - 2003b: The TRMM precipitation radar's view of shallow, isolated rain. J. Appl. Meteor., 42, 1519-1524.

- , - and I. Kraucunas, 2004: The tropical dynamical response to latent heating estimates derived from the TRMM precipitation radar. J. Atmos. Sci., 61, 1341-1358.

Sheppard, B. E., and P. Joe, 1994: Comparison of raindrop size distribution measurements by a Joss-Waldvogel disdrometer, a PMS 2DG spectrometer, and a POSS Doppler radar. J. Atmos. Oceanic Technol., 11, 874-887.

Short, D. A., P. A. Kucera, B. S. Ferrier, J. C. Gerlach, S. A. Rutledge, and O. W. Thiele, 1997: Shipboard radar rainfall patterns within the TOGA COARE IFA. Bull. Amer. Meteor. Soc., 78, 2817-2836.

Smith, E. A., and A. Mugnai, 1988: Radiative transfer to space through a precipitating cloud at multiple microwave frequencies. Part II: Results and analysis. J. Appl. Meteor., 27, 1074 1091.

_, and _ 1989: Radiative transfer to space through a precipitating cloud at multiple microwave frequencies. Part III: Influence of large ice particles. J. Meteor. Soc. Japan, 67, 739-755. 
- H. J. Cooper, G. J. Tripoli, and X. Xiang, 1992: Foundations for statistical-physical precipitation retrieval from passive microwave satellite measurements. Part I: Brightnesstemperature properties of a time-dependent cloud radiation model. J. Appl. Meteor., 31, 506-531.

Sobel, A. H., S. E. Yuter, C. S. Bretherton, and G. N. Kiladis, 2004: Large-scale meteorology and deep convection during TRMM KWAJEX. Mon. Wea. Rev., 132, 422-444.

Spencer, R. W., R. E. Hood, F. J. LaFontaine, E. A. Smith, R. Platt, J. Galliano, V. L. Griffin, and E. Lobl, 1994: High resolution imaging of rain systems with the Advanced Microwave Precipitation Radiometer. J. Atmos. Oceanic Technol., 11, 849-857.

Spooner, C. L., 2001: Dual-Doppler analysis of an oceanic tropical mesoscale system during the Kwajalein Experiment (KWAJEX). M.S. thesis, Atmospheric Sciences Group, Texas Tech University, $112 \mathrm{pp}$.

Steiner, M., R. A. Houze Jr., and S. E. Yuter, 1995: Climatological characterization of three-dimensional storm structure from operational radar and rain gauge data. J. Appl. Meteor., 34, 1978-2007.

Stith, J. L., J. E. Dye, A. Bansemer, A. J. Heymsfield, C. A. Grainger, W. A. Petersen, and R. Cifelli, 2002: Microphysical observations of tropical clouds. J. Appl. Meteor., 41, 97-117.

Tao, W.-K., and Coauthors, 2001: Retrieved vertical profiles of latent heat release using TRMM rainfall products for February 1998. J. Appl. Meteor., 40, 957-982.

Tesmer, J. R., and T. T. Wilheit, 1998: An improved microwave radiative transfer model for tropical oceanic precipitation. $J$. Atmos. Sci., 55, 1674-1688.

U.S. CLIVAR Pan American Implementation Panel, 2002: U.S CLIVAR Pan American research: A scientific prospectus and implementation plan. U.S. CLIVAR Office, $58 \mathrm{pp}$.

Wilheit, T. T., 1986: Some comments on passive microwave measurement of rain. Bull. Amer. Meteor. Soc., 67, 1226-1232.

Williams, M., and R. A. Houze Jr., 1987: Satellite-observed characteristics of winter monsoon cloud clusters. Mon. Wea. Rev., 115, 505-519.

Yanai, M. S., S. Esbensen, and J.-H. Chu, 1973: Determination of bulk properties of tropical clouds clusters from large-scale heat and moisture budgets. J. Atmos. Sci., 30, 611-627.

Yang, S., and E. A. Smith, 2000: Vertical structure and transient behavior of convective-stratiform heating in TOGA-COARE from combined satellite-sounding analysis. J. Appl. Meteor., 39, 1491-1513.

Yuter, S. E., and R. A. Houze Jr., 1995: Three-dimensional kinematic and microphysical evolution of Florida cumulonimbus. Part II: Frequency distributions of vertical velocity, reflectivity, and differential reflectivity. Mon. Wea. Rev., 123, 19411963.

- and,- 1997 : Measurements of raindrop size distributions over the Pacific warm pool and implications for $Z-R$ relations. J. Appl. Meteor., 36, 847-867.

Zipser, E. J., 1977: Mesoscale and convective-scale downdrafts as distinct components of squall-line circulation. Mon. Wea. Rev., 105, 1568-1589. 